\title{
SANIDAD Y PRODUCCIÓN ANIMAL
}

\section{Validación y estandarización de $\mathbf{1 0}$ pruebas semicuantitativas y cualitativas de diagnóstico paraclínico rápido como estrategia de abordaje clínico integral de los toxíndromes animales}

\author{
Jaramillo Hernández Dumar Alexander ${ }^{1}$, Roque Rodríguez Anita Isabel ${ }^{2}$ y \\ Rey Ríos Ángela Mayerli3 \\ ${ }^{1}$ MVZ. Dipl. Esp. cMSc. Profesor Farmacología, Toxicología y Clínica, \\ ${ }^{2} \mathrm{MV}$ - MSc. Profesora de clínica de pequeños animales, \\ ${ }^{3}$ Monitora del curso de Farmacología y Toxicología, Programa de Medicina \\ Veterinaria y Zootecnia. Grupo de investigación en Farmacología Experimental y \\ Medicina Interna - Élite. Escuela de Ciencias Animales. Universidad de los Llanos. \\ dumarjaramillo@gmail.com
}

\section{RESUMEN}

Introducción. El diagnóstico clínico de los toxíndromes atendidos en la consulta del médico veterinario está fundamentado en la obtención de los respectivos anamnésicos y catamnésicos que permitan suponer la disponibilidad de compuestos y/o tóxicos a los cuales se ha expuesto previamente el paciente; donde el conjunto de signos y síntomas clínicos no permiten discriminar agentes tóxicos comunes químicamente pero con comportamientos toxicocinéticos diversos. Esta acción se ve agravada por la falta de validación y estandarización de pruebas rápidas de diagnóstico paraclínico que direccionen la posibilidad de diagnóstico clínico específico de estos toxíndromes, soportando el tratamiento específico y aumento de probabilidades de recuperación del paciente. Objetivo. Validar y estandarizar 10 pruebas semicuantitativas y cualitativas de diagnóstico paraclínico rápido como estrategia de abordaje clínico integral de los toxíndromes animales. Metodología. De acuerdo a los principales toxíndromes asociados a la práctica clínica veterinaria, se determinó la búsqueda teórica científica, validación y estandarización a nivel de laboratorio y extrapolación a nivel de campo de 10 diferentes pruebas paraclínicas de diagnóstico rápido de resultados semicuantitativos y cualitativos de 10 tóxicos para las especies de interés 
zootécnico y animales de compañía. Los datos obtenidos fueron procesados a través del Programa OpenStat 4. Versión 7, Revisión 1; con un intervalo de confianza de 95\%. Resultados. Se construyeron, para su ejecución a nivel de campo a través de la organización de los respectivos kit de diagnóstico, diagramas de flujo y videos de desarrollo de cada una de las 10 diferentes pruebas validadas y estandarizadas, las cuales presentaron una alta sensibilidad ( $\ddot{x}$ 92\%) y especificidad ( $\ddot{x} 87 \%$ ) para determinar de forma directa o indirecta la posible incidencia de los siguientes tóxicos en los eventos tóxicos clínicos: insecticidas carbamatos típicos y atípicos, organofosforados con grupo nitro; metales pesados - arsénico, plomo; fármacos - sulfonamidas, fenotiazinas, salicilatos, alcoholes y aldehídos; herbicida - bipiridilos; y suplementos nutricionales en rumiantes - urea. Conclusiones. La posibilidad de contar con ayudas diagnósticas rápidas, confiables y de fácil desarrollo a nivel de campo; brindará herramientas clínicas contextualizadas a los profesionales del campo de las ciencias veterinarias en la toma de decisiones y prospectivas de recuperación de pacientes - poblaciones animales.

Palabras clave: toxíndrome, pruebas paraclínicas rápidas, clínica. 


\title{
Estudio toxicoepidemiológico participativo clínico veterinario de la ciudad de Villavicencio - Meta
}

\author{
Jaramillo Hernández Dumar Alexander ${ }^{1}$, Clavijo Sáenz Álvaro y otros ${ }^{2}$ \\ ${ }^{1}$ MVZ. Dipl. Esp. cMSc. Profesor Farmacología, Toxicología y Clínica, \\ ${ }^{2} E s t u d i a n t e s$ curso de Toxicología Veterinaria, Programa de Medicina Veterinaria y \\ Zootecnia. Grupo de investigación en Farmacología Experimental y Medicina \\ Interna - Élite. Escuela de Ciencias Animales. Universidad de los Llanos. \\ dumarjaramillo@gmail.com
}

\section{RESUMEN}

Introducción. Los orígenes y agentes implicados en los cuadros de toxicidad clínica en la medicina veterinaria se encuentran en constante desconocimiento por parte del profesional. La razón para esta situación se fundamenta en la falta de información confiable sobre los principales agentes tóxicos asociados a los toxíndromes comunes de una población animal. Objetivo. Establecer los principales agentes tóxicos asociados a los toxíndromes en animales de la ciudad de Villavicencio. Metodología. Se realizó un estudio toxicoepidemiológico participativo descriptivo donde los profesionales del sector de las ciencias veterinarias asociados al trabajo clínico en la ciudad de Villavicencio aplicaron una encuesta epidemiológica basada en los principales hechos implicados en la ocurrencia de toxíndromes. La selección de los centros clínicos veterinarios se estableció por regionalización, seguida de estadística estratificada para obtener un total de 86 encuestas aplicadas. Los datos obtenidos fueron procesados a través del Programa Epi Info ${ }^{\text {TM }}$ versión 3.5.3, 2011; con un intervalo de confianza de 95\%. Resultados. Las encuestas diligenciadas reportaron la siguiente distribución de los principales agentes asociados a toxíndromes: rodenticidas - Aldicarb (Campeón) 30\%, Fluoracetato sódico (Guayaquil) 22,7\% Brodifacouma (Klerat $\AA$ ) 4,7\%, Estricnina (Mata-ratas) 1,3\%; insecticidas - Clorpirifos (Lorsban®) $16 \%$ y Amitraz (Amitraz ${ }^{\circledR}$ ) 12\%; plantas - Pteridium aquilinum (helecho macho) 2,7\%, Allamanda sp. (mataganado) 0,7\%, y Enterolobium ciclocarpum (jaboncillo) 0,7\%; Fármacos - Ivermectina 2,7\%, Multivitamínicos y minerales 1,3\% y Atropina 0,7\%; toxinología - accidente ofídico bothrópico 1,3\% y botulismo 1,2\%; otros $2 \%$. Del 
total de 103 casos de posibles toxíndromes en especies de interés zootécnico atendidos por los profesionales encuestados, las especies de mayor distribución fueron los caninos $(52,4 \%)$, felinos $(35 \%)$, bovinos $(7,8 \%)$, equinos $(4,8 \%)$; el grupo etario de mayor frecuencia de presentación fueron los adultos $(57,8 \%)$; la principal vía de intoxicación fue la enteral $(60,2 \%)$, el principal contexto del toxíndrome fue el hogar (49,4\%), el estado clínico del paciente intoxicado fue crítico $(48 \%)$ y las alteraciones neurológicas fueron el principal grupo de signos clínicos (43,8\%). Conclusiones. La información obtenida del presente estudio toxicoepidemiológico participativo brinda los cimientos sólidos en la construcción de la primera base de datos de agentes tóxicos comunes en los cuadros clínicos asociados a toxíndromes en animales de la ciudad de Villavicencio.

Palabras clave: toxíndrome, toxicoepidemiología participativa, clínica veterinaria. 


\section{Evaluación del posible toxíndrome agudo de la ahuyama (Cucurbita maxima)} en caninos y el papel de los derivados de las metilxantinas como antídoto

Jaramillo Hernández Dumar Alexander ${ }^{1}$, Roque Rodríguez Anita Isabel ${ }^{2}$, Tamayo Rojas Doris Juliette ${ }^{3}$, Correa Apolinar Diana Carolina ${ }^{4}$ y

Carolina Pérez Audrey ${ }^{5}$

${ }^{1}$ MVZ. Dipl. Esp. cMSc. Profesor Farmacología, Toxicología y Clínica, ${ }^{2} \mathrm{MV}$ - MSc. Profesora de clínica de pequeños animales,

${ }^{3}$ MVZ. Joven Investigadora programa Virginia Gutiérrez de Pineda.

${ }^{4-5}$ Estudiantes proyecto de investigación - EPI - Programa de Medicina Veterinaria y Zootecnia. Grupo de investigación en Farmacología Experimental y Medicina Interna - Élite. Escuela de Ciencias Animales. Universidad de los Llanos. dumarjaramillo@gmail.com

\section{RESUMEN}

Introducción. La ahuyama (Cucúrbita Máxima) pertenece a la familia de las cucurbitáceas, pertenecientes a la familia de las dicotiledoneas. Su componente activo son las cucurbitacinas, que han sido usadas en numerosos estudios por sus propiedades farmacológicas. Objetivo. El objetivo de este estudio fue documentar las alteraciones clínicas y subclínicas de caninos sanos expuestos a una única dosis de ahuyama y la posibilidad de vincular como tratamiento específico los derivados de las metilxantinas. Metodología. Para el experimento se utilizaron 24 caninos machos, sanos, rango de edad de $3-5$ años y peso vivo de 10 a $20 \mathrm{~kg}$, los cuales se distribuyeron de forma aleatoria en 24 caniles, organizados en 4 grupos, cada grupo compuesto por 6 animales experimentales (grupo A, B, C y D). Los caninos del grupo A recibieron vía oral $500 \mathrm{mg} / \mathrm{kg}$ de materia seca de ahuyama (MSA); al grupo B 1 $\mathrm{g} / \mathrm{kg}$ MSA P.O, al grupo C $5 \mathrm{~g} / \mathrm{kg}$ MSA P.O y al grupo D $200 \mathrm{~g}$ de ahuyama cocida P.O (preparación en forma casera tradicional). A Los caninos se les evaluó el SNC y el SNP (reflejos espinales, pares craneales y pruebas posturales); además pruebas paraclínicas (perfil hemático, perfil hepático y perfil renal) en tres momentos diferentes, T0: 1 hora antes de la exposición a la ahuyama, T1: 4 horas posexposición, T2: 24 horas posexposición; documentando el tiempo de aparición, progreso y resolución de signos y síntomas compatibles con el toxíndrome neuromuscular. Los datos obtenidos se procesaron utilizando el programa Open Stat $4 ®$ Versión 9.0, la prueba de Fisher y análisis de varianza de 
una vía - comparación de medias Tukey-Kramer, se realizó dependiendo de la naturaleza de los datos; asumiendo una $p<0.05$. Resultados. Los resultados de los estudios clínicos de los grupos A, B, C y D; en los tiempos T0, T1 y T2 (reflejos espinales $=\bar{x} 2 \pm 0$, pares craneanos $=\bar{x} 2 \pm 0$ y pruebas posturales $=\bar{x} 2 \pm 0$ ) y paraclínicos no logran evidenciar diferencias significativas $(p<0.05)$ entre los grupos de animales experimentales. Conclusiones. Estos hallazgos sugieren que la exposición aguda a Cucurbita maxima en Caninos clínicamente sanos, utilizados en este estudio, no ocasiona signos clínicos de intoxicación, presumiendo que el toxindrome neuromuscular necesita de alteraciones sistémicas previas, como puede ser la alteración de vías de detoxificación y/o eliminación de las cucurbitacinas, principales metabolitos asociados al toxindrome. El tratamiento con derivados de las metilxantinas para este toxíndrome, tiene su principio farmacológico, basado en el antagonismo sobre el receptor de Adenosina (A1) generado por estos fármacos, en coherencia con el efecto agonista $A 1$ de las cucurbitacinas, lo cual explica de forma presumible las alteraciones clínicas a nivel del SNC y SNP de los caninos expuestos a la ahuyama.

Palabras clave: adenosina, cucurbitacina, toxíndrome. 


\section{Toxíndrome asociado a Crotalaria pallida en el modelo deintoxicación subcrónica en el ovino}

Jaramillo Hernández Dumar Alexander ${ }^{1}$, Roque Rodríguez Anita Isabel ${ }^{2}$, Veloza Luis Carlos ${ }^{3}$, Cifuentes Diana Consuelo ${ }^{4}$, y Tamayo Rojas Doris Juliette ${ }^{5}$

${ }^{1}$ MVZ. Dipl. Esp. cMSc. Profesor Farmacología, Toxicología y Clínica,

${ }^{2} \mathrm{MV}$ - MSc. Profesora de clínica de pequeños animales

${ }^{3} \mathrm{MV}$. Esp. Profesor Patología,

${ }^{4}$ MVZ. Esp. MSc. cPhD. Profesora de Clínica grandes animales

${ }^{5}$ MVZ. Joven Investigadora programa Virginia Gutiérrez de Pineda. Grupo de investigación en Farmacología Experimental y Medicina Interna - Élite. Escuela de Ciencias Animales. Universidad de los Llanos. dumarjaramillo@gmail.com

\section{RESUMEN}

Introducción. Las plantas de género Crotalaria pertenece a la familia Fabaceae que comprende cerca de 600 especies. El principal uso de estas plantas se produce en la agricultura asociada a los abonos verdes para ayudar a la preparación del suelo por su alta capacidad de fijación del nitrógeno atmosférico en el suelo. Estas plantas contienen un alcaloide pirrolizidinico llamado monocrotalina, la cual es una fitotoxina que ha sido bien documentada en toxicidad hepática y cardiopulmonar para los animales, incluidos los rumiantes y humanos. Objetivo. El objetivo del presente estudio fue evaluar los efectos tóxicos de Crotalaria pallida en ovinos bajo el modelo subcrónico de toxicidad por plantas. Metodología. El experimento utilizó 6 ovinos machos criollos de 6 a 12 meses de edad, peso promedio $27 \mathrm{~kg}$. Los animales fueron sometidos a un tiempo experimental de 28 días, se mantuvieron en jaulas con agua y heno (Dichantium

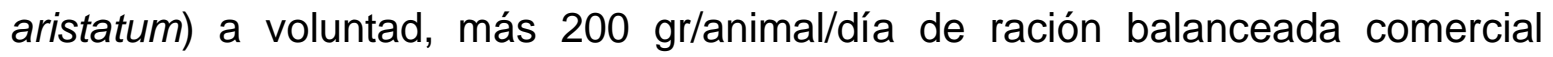
(Contegral®); se distribuyeron aleatoriamente en dos grupos experimentales: 2 animales grupo control (G1) y el grupo experimental con 4 animales (G2), dieta + $4,9 \%$ del peso vivo de materia verde de C. pallida mezclada en la ración balanceada. El examen clínico diario, la toma de peso semanal y el muestreo sanguíneo durante los días 0,14 y 28 del experimento fueron las acciones realizadas sobre los animales experimentales. Resultados. Perfil hemático: recuento del número de glóbulos rojos (G1̄ $9.2 \pm 0.4$ y G2 $9.4 \pm 0.8 \times 10^{6} / \mu \mathrm{L}$ ), 
hematocrito ( $\mathrm{G} 1 \overline{\mathrm{x}} 26.1 \pm 2.64$ y G2 27,7 $\pm 2 \%$ ), recuento diferencial leucocitario (G1 $\bar{x} 9.7 \pm 1.5$ y G2 $9.3 \pm 0.3 \times 10^{3} / \mu \mathrm{L}$ ), neutrófilos ( $\mathrm{G} 1 \overline{\mathrm{x}} 3.5 \pm 0.2$ y G2 $3.3 \pm$ $0.3 \times 10^{3} / \mu \mathrm{L}$ ), linfocitos (G1 $\bar{x} 5.3 \pm 0.5$ y G2 $5.1 \pm 0.2 \times 10^{3} / \mu \mathrm{L}$ ) eosinofilos (G1 $\bar{x}$ $0,67 \pm 0.19$ y G2 $0.49 \pm 0.21 \times 10^{3} / \mu \mathrm{L}$ ); perfil hepático AST (G1 $\bar{x} 86.8 \pm 12$ y G2 $80.3 \pm 7.1 \mathrm{U} / \mathrm{L})$, GGT (G1 $\bar{x} 41.6 \pm 5.8$ y G2 $46.1 \pm 6.2 \mathrm{U} / \mathrm{L}$ ), perfil renal BUN (G1 $\bar{x}$ $8.61 \pm 1.1$ y G2 $9.6 \pm 0.9 \mathrm{mg} / \mathrm{dL})$ y creatinina (G1 $\bar{x} 2.83 \pm 1$ y G2 $0.83 \pm 1.5$ $\mathrm{mg} / \mathrm{dL}$ ). El día 28 de consumo de $C$. pallida, se sacrificó un animal de cada grupo G1 y G2, para el estudio anatomopatológico e histopatológico con tinción HE; donde se evidenció engrosamiento moderado de los septos alveolares en pulmón, cambio vacuolar severo en hígado y proteinuria moderada en riñón en el animal del grupo G2. Los estudios clínicos y paraclínicos no evidenciaron diferencias significativas $(p<0.05)$ entre los grupos experimentales. Conclusiones. Estos hallazgos sugieren que la exposición subcrónica a la dosis administrada de Crotalaria pallida en ovinos no ocasiona signos clínicos y paraclínicos de intoxicación, pero se evidencian cambios micro estructurales en los órganos vitales para procesos de hematosis, detoxificación y excreción de xenobióticos; presumiendo que el alcaloide pirrolizidínico monocrotalina puede tener un papel fundamental en este toxíndrome multisistémico subclínico.

Palabras clave: alcaloides pirrolizidinicos, toxíndrome, monocrotalina. 


\section{Prevalence and characterization of influenza viruses in diverse species in}

\section{Los Llanos, Colombia}

Karlsson Erik $A^{1}$, *Ciuoderis Karl'2, Freiden Pamela ${ }^{1}$, Seufzer Bradley ${ }^{1}$, Jones Jeremy $\mathrm{C}^{1}$, Johnson Jordan ${ }^{1}$, Parra Rocio ${ }^{3}$, Gongora Agustín ${ }^{3}$, Cárdenas Darío ${ }^{4}$, Barajas Diana ${ }^{4}$, Osorio Jorge $E^{2}$ and Schultz-Cherry Stacey ${ }^{1}$

${ }^{1}$ Department of Infectious Diseases, St Jude Children's Research Hospital, Memphis, TN 38105, USA; ${ }^{2}$ Department of Pathobiological Sciences, University of Wisconsin-Madison School of Veterinary Medicine, Madison, WI 53706, USA;

${ }^{3}$ GIRGA Group, University de los Llanos School of Veterinary Medicine, Villavicencio 500001, Colombia and ${ }^{4}$ University Cooperativa de Colombia School of Veterinary Medicine, Villavicencio, 500001 Colombia.

Stacey.Schultz-cherry@stjude.org

\section{RESUMEN}

Introduction. While much is known about the prevalence of influenza viruses in North America and Eurasia, their prevalence in birds and mammals in South America is largely unknown. To fill this knowledge gap and provide a baseline for future ecology and epidemiology studies, we conducted 2 years of influenza surveillance in the eastern plains (Los Llanos) region of Colombia. Materials and methods. Real-time reverse transcriptasepolymerase chain reaction (RT-PCR) identified influenza viruses in wild birds, domestic poultry, swine and horses. Results. Prevalence ranged from $2.6 \%$ to $13.4 \%$ across species. Swine showed the highest prevalence and were infected primarily with 2009 pandemic H1N1 ( $\mathrm{pH} 1 \mathrm{~N} 1)$ viruses genetically related to those in humans. In addition, we isolated H5N2 viruses from two resident species of whistling ducks (genus Dendrocygna) that differed completely from previous South American isolates, instead genetically resembling North American wild bird viruses. Both strains caused low pathogenicity in chickens and mammals. Conclusions. The prevalence and subtype diversity of influenza viruses isolated from diverse species within a small area of Colombia highlights the need for enhanced surveillance throughout South America, including monitoring of the potential transmissibility of low-pathogenic H5N2 viruses from wild birds to domestic poultry and the emergence of reassortant viruses in domestic swine.

Key words: influenza viruses, several species 


\section{Seasonal variation and natural infection of Lutzomyia antunesi (Diptera:}

Psychodidae: Phlebotominae), an endemic species in the Orinoquia region of Colombia

Vásquez Trujillo Adolfo ${ }^{1}$ Góngora Orjuela Agustín ${ }^{2}$, Prieto Suárez Edgar ${ }^{3}$, Palomares Jairo Enrique ${ }^{4}$, Buitrago Alvarez Luz Stella ${ }^{5}$, y González Reina Angélica ${ }^{1}$

${ }^{1}$ Corporación para la Investigación en Salud Tropical, Villavicencio, Meta, Colombia, ${ }^{2}$ Escuela de Ciencias Animales, Universidad de los Llanos,

Villavicencio, Meta, Colombia, ${ }^{3}$ Departamento de Salud Pública, Facultad de Medicina, Universidad Nacional de Colombia, Bogotá DC, Colombia ${ }^{4}$ Clinical Sciences Department, Colorado State University, Fort Collins, CO, USA ${ }^{5}$ Laboratorio de Entomología, Secretaria de Salud del Meta, Villavicencio, Meta, Colombia agongora@unillanos.edu.co

\section{RESUMEN}

Introduction. Lutzomyia antunesi has been commonly reported in outbreaks of cutaneous leishmaniasis $(\mathrm{CL})$ in the Orinoquia region of Colombia. The bionomics of this species were studied in the municipality of Villavicencio (Meta, Colombia). Matherials and Methods. Sandflies were captured over the course of one week per month for one year in intradomiciliary, peridomiciliary and extradomiciliary housing areas. The captures were performed from 06:00 pm-06:00 am using CDC light traps and the females were processed for polymerase chain reaction (PCR) to detect Leishmania spp. Results. A total of 22,097 specimens and 19 species were captured of which Lutzomyia antunesi (89\%) and Lutzomyia walkeri (5\%) were the most abundant. Other species recognised as anthropophilic (Lutzomyia panamensis, Lutzomyia gomezi, Lutzomyia flaviscutellata and Lutzomyia fairtigi) were present in very low abundance $(<2 \%)$. Natural infection with Leishmania spp was detected using PCR in L. antunesi, L. panamensis and L. flavicutellata, showing infection rates of $1 \%, 4.8 \%$ and $7.5 \%$, respectively. Conclusions. The present paper provides information on various ecological aspects of $L u$. antunesi. An analysis of seasonality shows that this species increases in abundance in the hottest months (December, January and February), directly correlating with the 
maximum temperature and inversely correlating with precipitation. The natural infection rate is associated with the peaks of highest abundance.

Key words: Lutzomyia antunesi, Orinoquia region 


\section{Seroprevalencia a 10 serovares de Leptospira spp de una subpoblación equina, de 6 municipios del Meta y Guaviare.}

Rey Riaño Luz A. ${ }^{1}$, Pineda Rojas Nicolás F. ${ }^{1}$, Góngora Agustín ${ }^{2}$, Parra Jorge L ${ }^{3}$, Patiño Rocío E. ${ }^{4}$

${ }^{1}$ Estudiantes MVZ, ${ }^{2}$ MV, Dr. Sci. Universidad de los Llanos, ${ }^{3} \mathrm{DMV}, \mathrm{MSc}$., Corpoica Cl la Libertad, ${ }^{4}$ Bacteriologa MSc Corpoica Cl Tibaitatá.

\section{agongora@unillanos.edu.co}

\section{RESUMEN}

Introducción. La leptospirosis es una enfermedad que afecta diversas especies animales y es la zoonosis más difundida en el mundo. En la Orinoquia, los equinos son un factor fundamental para la actividad ganadera y en las actividades recreativas y deportivas. No existen estudios poblacionales de leptospirosis en esta especie, basados en serología en la Orinoquia y el país. Materiales y métodos. Se realizó un estudio transversal, con numero y selección de unidades de muestreo por conveniencia, a 94 equinos de los municipios de Villavicencio (n:16), San Martin (n:14), Restrepo (n:8), Puerto López (n:21), Puerto Lleras (n:18) y San José del Guaviare (n:17). Se tomaron con tubos vacutainer ${ }^{\circledR}$ estériles al vacio, sangre de la vena yugular externa, que se traslado en cadena de frio hasta el laboratorio donde se centrifugó, se separó el coagulo del suero y se almacenó a $-20{ }^{\circ} \mathrm{C}$, hasta su análisis por la prueba de microaglutinación lisis (MAT) a 10 serovares de Leptospira spp en el Laboratorio de leptospirosis de Corpoica en Tibaitatá. Los sueros fueron probados desde una dilución inicial de 1:50, en diluciones dobles hasta la dilución en la cual el $50 \%$ o más de las Leptospira no eran aglutinadas por la dilución del suero. Resultados. Se consideró "seropositivo" una aglutinación en MAT $\geq 1: 50$, en razón de que los serovares utilizados eran incidentales para la especie equina, y que esta especie está en contacto permanente con otras especies domésticas y silvestres que tienen serovares específicos, como roedores-plaga, roedores silvestres, caninos, cerdos, bovinos. La seroprevalencia de la subpoblación fue: L. Pomona 41.5\%, L. icterohaemorragiae $40.4 \%$, L. grippothyposa $24.5 \%$, L. javanica $23.4 \%$, L. canícola $16 \%, L$ hardjoprajitno $10.6 \% \%$, $L$ tarassovi $7,4 \%$, L. hebdomadis $7,4 \%$, L. wolffi 
$2,1 \%$ y $L$. Bratislava $1,1 \%, 23.4 \%$ de los animales no mostraron reactividad serológica a los 10 serovares, mientras a uno o más serovares de $76.6 \%$. La mayor frecuencia de los títulos para la dilución 1:50 fue L. javanica 21.3\%, icterohaemorragiae 12.8\%, L hardjoprajitno $10.6 \%$ y L. Pomona10.6\%, en títulos 1:100 L. icterohaemorragiae 17\%, L. grippothyposa $10.6 \%$ y L. Pomona $9.6 \%$, para 1:200 L. Pomona 17\% y L. icterohaemorragiae 8.5\%. La serorespuesta a 10 mas serovares, se encontró asociada a los grupos de edad $\left(\mathrm{Chi}^{2}=6,393 ; \mathrm{gl}=2 ; \mathrm{p}<\right.$ 0,041 ), siendo superior a medida que el grupo etáreo era mayor (potros $57,1 \%$, jóvenes $77,4 \%$ y adultos $85,7 \%$ ), en tanto, el sexo, fue independiente de la reactividad $(p>0,05)$. La mayor copositividad entre serovares fue $L$. pomona - $L$. icterohamorragiae $23.4 \%$. Conclusiones. La leptospirosis en los equinos tiene una infección importante, con serovares asociados a otras especies domesticas y silvestres, como roedores, caninos, porcinos y bovinos, demostrando una compleja cadena epidemiológica, observable bajo el concepto de una sola salud.

Palabras clave: epidemiologia, MAT, equinos, serovar 


\section{Detección de anticuerpos a la arteritis viral en equinos de la Orinoquia.}

Góngora Orjuela Agustín ${ }^{1}$, Barrandeguy María ${ }^{2}$, Ciuderis Aponte Karl A , ${ }^{1}$ Grupo de Investigación en Reproducción y Genética Animal, Universidad de los Llanos.

2Laboratorio de Virus Equinos, Instituto de Virología CICVyA INTA-Argentina. ${ }^{3}$ Department of Pathobiological Sciences, University of Wisconsin-Madison School of Veterinary Medicine, Madison, WI 53706, USA. agongora@unillanos.edu.co

\section{RESUMEN}

Introducción. La arteritis viral equina (AVE) es una enfermedad infecciosa propia de esta especie, que además afecta asnos, mulas y cebras. La Organización Mundial de Sanidad Animal (OIE) la incluyó en la lista de enfermedades de notificación obligatoria en razón de su potencial trasmisión a poblaciones libres, donde las principales fuentes de infección son los animales portadores o el semen contaminado con el virus. En Colombia la AVE se mantiene como una enfermedad exótica, sin embargo la alta importación de equinos en los últimos años de países que han presentado recientes brotes, más la presencia de cuadros clínicos compatibles con la enfermedad hace presumir de su presencia. Materiales y métodos. Se realizó un estudio transversal con selección de individuos por conveniencia en $n=100$ equinos provenientes de los municipios de Villavicencio $(n=19)$, San Martin ( $n=10)$, Restrepo $(n=10)$, Puerto López $(n=10)$, Puerto Lleras $(n=10)$, Yopal $(n=10)$, Arauquita $(n=7)$, Arauca $(n=3)$, Puerto Gaitán $(n=10)$, San José del Guaviare $(n=10)$ y Guamal $(n=1)$. De cada individuo, se obtuvo aproximadamente $5 \mathrm{ml}$ de sangre de la vena yugular en tubos vacutainer ${ }^{R}$ y transportadas a $4^{\circ} \mathrm{C}$ hasta el Laboratorio de Reproducción y Genética Animal de la Universidad de los Llanos. Luego de la retracción del coagulo se centrifugaron a 3.500 RPM por 5 minutos y el suero obtenido fraccionado en tubos Eppendorf ${ }^{R}$ de $1.0 \mathrm{ml}$ y conservados a $-20^{\circ} \mathrm{C}$ hasta su análisis. Los sueros se procesaron en el Instituto de Virología-Centro de Investigaciones en Ciencias Veterinarias y Agronómicas (INTA-Argentina), mediante la técnica de microseroneutralización frente a virus de AVE (cepa vacunal-Arvac). Se utilizaron como control positivo y negativos sueros equinos de referencia internacional provistos por el Dr. P. 
Timoney, del Gluck Equine Center (Universidad de Kentucky-USA), se siguió el protocolo descrito en el manual de la OIE sobre animales terrestres 2012. Resultados. No se encontraron reactores positivos en las muestras analizadas, lo que sugiere nuevos estudios en una población más amplia. Conclusiones. Los resultados negativos en la población estudiada, sugieren la no presencia del virus en una amplia zona de la Orinoquia dada la procedencia de las muestras, sin embargo sugieren nuevos estudios en otras regiones del país, especialmente las de mayor población equina lo cual permitan extremar las medidas sanitarias y continuar manteniendo el estado libre a esta enfermedad.

Palabras clave: orinoquia, virus, equinos 


\title{
Huella inmunológica de los virus HVE-1 y HVE-4, asociados a la
}

\section{Rinoneumonitis equina, en seis localidades de la Orinoquia Colombiana.}

\author{
Góngora Agustín ${ }^{1}$, Parra Jorge L. ${ }^{2}$, Ciuderis Karl A. ${ }^{3}$ \\ ${ }^{1} \mathrm{MV}$, Dr. Sci. Grupo de Investigación en Reproducción y Genética Animal, \\ Universidad de los Llanos \\ 2DMV, MSc., Corpoica, Centro de Investigaciones la Libertad. \\ ${ }^{3} \mathrm{MVZ}$, Department of Pathobiological Sciences, University of Wisconsin-Madison \\ School of Veterinary Medicine, Madison, WI 53706, USA. \\ agongora@unillanos.edu.co
}

\section{RESUMEN}

Introducción. La Rinoneumonitis Equina es una enfermedad infecciosa producida por dos tipos de virus, el herpes virus equino 1 (HVE-1) y herpes virus equino tipo 4 (HVE-4). En los países en donde la enfermedad ha sido reportada, las pérdidas económicas son considerables y están representadas en la muerte en animales jóvenes por infecciones respiratorias y abortos en la gestación tardía. En Colombia hasta el año 2001 no se tenía conocimiento de esta enfermedad, sin embargo estudios recientes señalan su presencia en algunas regiones del país. Objetivo. Evidenciar en forma indirecta, la presencia de los herpes virus equino 1 y 4 (HVE1 y HVE-4) en seis municipios de la Orinoquia Colombiana, mediante detección de anticuerpos IgG por prueba serológica de Elisa. Materiales y Métodos. Se realizó un estudio transversal, con número y selección de unidades de muestreo por conveniencia, a 260 equinos de los Municipios de: Arauca (48), San Martin (52), San José del Guaviare (41), Puerto López (46), Puerto Gaitán (25) y Yopal (48). Se tomaron $7,5 \mathrm{ml}$ de sangre de la vena yugular externa en tubos vacutainer ${ }^{R}$ estériles, al vacio, sin anticoagulante, las muestras fueron centrifugadas a 3.5000 RPM por 10 minutos y los sueros obtenidos, fraccionados por duplicado en crioviales Eppendorf de $1,0 \mathrm{ml}$ y almacenados a $-20^{\circ} \mathrm{C}$ hasta su análisis. Se utilizó como prueba diagnóstica un Kit comercial de Elisa indirecto que discrimina los anticuerpos a HVE-1 y HVE-4 (SvanovirR, Svanova Biotech AB Uppsala, Sweden). Resultados. La seropositividad de la población evaluada fue de $12.7 \%$ para HVE1 y $70.4 \%$ para HVE-4, y una copositividad de 12.7\%, todos los equinos seropositivos a HVE-1 lo fueron también a HVE-4. La seropositividad para HVE-1 
por localidad fue San Martin (34.6\%), Arauca (10.4\%), Puerto López (8.7\%), Yopal (6.3\%), San José del Guaviare (4.9), Puerto Gaitán (4.0\%); mientras al HVE-4 fue: $80.8 \%, 77.1 \%, 45.7 \%, 79.2 \%, 65.9 \%, 72.0 \%$ para los mismos municipios. La seropositividad por sexo para el HVE-1 fue hembras $17.8 \%$ y Machos $9.2 \%$, para el HVE-4 hembras $75.7 \%$ y machos $70.0 \%$. La seropositividad por grupo etáreo para HVE-1 fue potros y potrancas $53.6 \%$, jóvenes $41.8 \%$ y adultos $39.7 \%$ y para el HVE-4 de $78.6 \%, 76.4 \%$ y $63.6 \%$ para los mismos grupos respectivamente. Conclusiones. Se identificó la presencia de reactores positivos a los dos virus, siendo mayor la seropositividad para el HVE-4, lo que sugiere la presencia de los dos virus en la población equina de la región, siendo necesarios más estudios que asocien infección-huella inmunológica y enfermedad.

Palabras clave. Rinoneumonitis equina, virus HVE-1 y HVE-4 


\title{
Análisis de la consolidación ósea del radio de conejos utilizando hidroxiapatita con alandronato
}

\author{
Roque Rodríguez Anita I. ${ }^{1}$ MV, MSc; Pedraza Castillo Natalia ${ }^{1}$ MVZ, MSc; \\ Cifuentes Diana C. MVZ, MSc, cPhD; Rodriguez Willinton MVZ; Zambrano Lugo \\ Daniel E. ${ }^{1}$ MVZ y Jaramillo Hernández Dumar A. ${ }^{1}$ MVZ, Esp, cMSc. \\ ${ }^{1}$ Grupo de Investigación en Farmacología experimental y medicina interna - \\ ÉLITE, Centro Clínico Veterinario, Facultad de Ciencias Agropecuarias, \\ Universidad de los Llanos, Villavicencio, Colombia. \\ anyroque@hotmail.com
}

\section{RESUMEN}

Introducción. A lo largo de los años la utilización progresiva de materiales de fosfato de calcio como implantes óseos, ha llevado a demostrar el alto potencial como sustituto óseo de la hidroxiapatita Ca10 (PO4)6(OH)2 en ortopedia. Histopatológicamente fue demostrado que el alandronato utilizado en un flap mucoperiosteo de la mandíbula de ratones, reduce la reabsorción ósea y permite una rápida formación del callo óseo, además sugiere que este bifosfonato puede ser usado como ayuda en la terapia para reducir la reabsorción de hueso, que puede ocurrir en el transcurrir de una cirugía ortopédica y en pacientes seniles. Objetivo. Evaluar el efecto de la hidroxiapatita con Alandronato sobre la consolidación ósea del radio de conejas adultas. Métodos. Fueron utilizadas seis (6) conejas de 6 meses de edad, de $4 \mathrm{Kg}$. se les realizo dos fallas óseas de $2 \mathrm{~mm}$ de diámetro en el tercio distal del radio de ambos miembros. En el tercio distal del miembro derecho fue implantada la Hidroxiapatita sintética (HAP-91) con Alandronato: $4.2 \mathrm{mg}$ de Alandronato y $200 \mathrm{mg}$ de Hidroxiapatita y el miembro izquierdo es el control. Las radiografías fueron realizadas los días 8, 30, 60, 90 post-operatorios. La evaluación densitométrica fue realizada en la UNESP de Jaboticabal-Brasil, a los días 8, 30, 60 y 90 días del periodo post-operatorio. Resultados. La comparación entre medias corrobora que el grupo tratamiento HAP-AL, tuvo un mejor comportamiento a lo largo del experimento, obteniendo una media general de $19.84 \mathrm{mg} / \mathrm{cm}^{2}$, en comparación con la obtenida para el grupo control que fue de $9.46 \mathrm{mg} / \mathrm{cm}^{2}$ Aplicando el Test de Tukey ( $p>0.05$ ) se evidencio que las medias presentaron diferencias significativas entre el grupo 
control y el grupo tratamiento HAP-AL a los 8, 30,60 y 90 días pos-operatorios. Conclusiones. Clínicamente el biomaterial de hidroxiapatita con alandronato presenta ausencia de reacciones adversas demostrando su biocompatibilidad. Densitométricamente se observa un aumento significativo y progresivo al tiempo de la densidad ósea con respecto al control. El biomaterial de la hidroxiapatita con alandronato acelera el proceso de reparación ósea demostrando que posee una capacidad osteoconductora.

Palabras clave: Reparación de fracturas, densitometría ósea, biocompatibilidad. 


\section{Análisis de la consolidación ósea del radio de conejos utilizando hidroxiapatita con liposomas}

Roque Rodríguez Anita I. ${ }^{1}$ MV, MSc; Pedraza Castillo Natalia ${ }^{1}$ MVZ, MSc, Zambrano Lugo Daniel E. ${ }^{1}$ MVZ; Jaramillo Hernández Dumar A. ${ }^{1}$ MVZ, Esp, cMSc

y Díaz Olga, MVZ.

${ }^{1}$ Grupo de Investigación en Farmacología experimental y medicina interna ÉLITE, Centro Clínico Veterinario, Facultad de Ciencias Agropecuarias, Universidad de los Llanos, Villavicencio, Colombia. 2Estudiantes curso de Toxicología Veterinaria, Programa de Medicina Veterinaria y Zootecnia, Universidad de los Llanos. anyroque@hotmail.com

\section{RESUMEN}

Introducción. Los substitutos óseos deben ser bio-activos, bio-compatibles, biodegradables o bio-absorbidos, favorecer el crecimiento óseo por conducción y si es posible por inducción. Las formas sintéticas de hidroxiapatita (HA) resultan ser químicamente similares a la hidroxiapatita natural del hueso. Los resultados obtenidos en su implantación in vivo han demostrado ausencia de toxicidad, no provocando inflamación ni respuesta a cuerpo extraño. Se ha demostrado la aposición directa de nuevo hueso a la hidroxiapatita. La formación de enlaces internos entre la neoformación ósea y la hidroxiapatita es una gran ventaja del uso de la HA como sustituto de injerto. Objetivo. Evaluar el efecto de la hidroxiapatita con Liposomas en la consolidación ósea del radio de conejas adultas. Métodos. Los animales se sometieron a cirugía en donde se realizó dos fallas óseas de 2 $\mathrm{mm}$ de diámetro en el tercio distal del radio de ambos miembros. En el miembro derecho fue implantada la hidroxiapatita con Liposomas y el miembro izquierdo el control. La evaluación radiográfica se realizó a los 8, 30, 60 y 90 días del posoperatorio. La evaluación densitométrica fue realizada en la UNESP de Jaboticabal-Brasil, a los días 8, 30, 60 y 90 días del periodo post-operatorio a partir de las imágenes radiográficas, determinando así las diferencias cualitativas y cuantitativas en la reacción periosteal durante el tiempo transcurrido. Resultados. Aplicando la prueba t-student, se afirma que la hidroxiapatita con liposomas acelera el proceso de consolidación ósea, los resultados se evidencian en el análisis obtenido con diferencias significativas entre el grupo control y el grupo 
tratado. Se observa en los resultados, que la densidad ósea fue significativamente mayor en el grupo tratado con hidroxiapatita con liposomas comparado con el grupo control $(p<0.05)$. Conclusiones. La densidad ósea fue significativamente mayor en los animales tratados con hidroxiapatita con liposomas comparada con el grupo control. El biomaterial estimula precozmente el inicio del proceso de reparación ósea, demostrando que posee una mayor capacidad osteoconductora comparado con el control. Radiográficamente la radiopacidad en torno al biomaterial fue progresiva en el tiempo, indicando osteogénesis y formación de tejido óseo maduro a los 30 días en los animales tratados.

Palabras clave: Biomaterial, reparación ósea, osteoinducción. 


\section{Determinación de parásitos gastrointestinales en cinco explotaciones}

\section{bovinas del departamento del Meta}

Urrea Sánchez Fabián M. ${ }^{1}$, García Martínez Gina $L^{2}$ y Manrique José Fernández ${ }^{3}$

${ }^{1 *}$ MVZ, Grupo de investigación en Genética y Reproducción Animal Universidad de los Llanos.

2 M.V.Z, MSc. Docente facultad de Ciencias Agropecuarias y Recursos Naturales Universidad de los Llanos.

${ }^{3}$ M.V-MSc. Docente facultad de Ciencias Agropecuarias y Recursos Naturales Universidad de los Llanos.

Fabian.urrea@unillanos.edu.co

\section{RESUMEN}

Introducción. Dentro de los principales problemas que afectan la sanidad animal en los bovinos, se encuentran el parasitismo gastrointestinal, que con mayor frecuencia ataca a los animales entre los 3 a 12 meses de edad ocasionando pérdidas económicas y disminuyendo la competitividad de las cadenas láctea y cárnica. Objetivo. Determinar la presencia de parásitos gastrointestinales en cinco explotaciones bovinas. Metodología. Previa invitación a los ganaderos de los municipios de Granada y Villavicencio Meta, a la participación en el proyecto, se aplicó una encuesta para indagar sobre las variables de manejo y sanidad animal en los predios vinculados al estudio. Posteriormente en cada finca, se seleccionaron entre 50 a 80 terneros, a los cuales se les realizó examen clínico y toma de muestra de materia fecal, las muestras rotuladas se transportaron refrigeradas al laboratorio de parasitología veterinaria de la Universidad de los Llanos y mediante la técnica de flotación modificada de McMaster se determinó y cuantificó la presencia de huevos por gramo (HPG) de nemátodos; y ooquistes por gramo (OPG) de coccidia. Las variables de estudio se analizaron mediante la estadística descriptiva. Resultados. De la muestra estudiada de 286 bovinos se encontró un $74,5 \%$ de animales con nematodosis, con un promedio general de 238 HPG tipo Strongyloidea, y un 59,4\% de bovinos con coccidiosis con un recuento general de 552 OPG de Eimeria sp. La carga parasitaria de nemátodos no es alta en contraste con el recuento de OPG de coccidia, siendo este el problema infeccioso parasitario relevante en la población de terneros en los 
predios estudiados. Conclusiones. La frecuencia y los recuentos de HPG de nemátodos nos podrían indicar que los productos utilizados como antihelmínticos no son eficientes para el control de los nemátodos en los predios estudiados.

Palabras claves: Eimeria, nematodosis y Strongyloidea. 


\section{Diagnóstico de bovinos seropositivos y persistentemente infectados con el virus de diarrea viral bovina en el Piedemonte Llanero}

Velasco Santamaría Yohana M., PhD Universidad de los Llanos, Facultad de Ciencias Agropecuarias y Recursos Naturales, Grupo de Investigación sobre Reproducción y Toxicología de Organismos Acuáticos - GRITOX, Km 12 vía

Puerto López, vereda Barcelona, Villavicencio - Meta, Colombia ymvelascos@unillanos.edu.co

\section{RESUMEN}

Introducción. El virus de diarrea viral bovina (VDVB) pertenece a la familia Flaviviridae y al género Pestivirus y pertenece al síndrome de aborto bovino, una entidad multifactorial responsable de disminución en las tasas de ovulación, fertilidad, sobrevivencia fetal y perinatal (aborto y momificación). La presencia de animales persistentemente infectados (PI) con el VDVB, constituyen los reservorios naturales diseminadores de la enfermedad. Se reporta que los animales PI son más importantes como reservorios ya que excretan altos niveles del virus por períodos de tiempo más prolongados y los animales con infección aguda pueden ser más importantes para la generación de nuevas variantes antigénicas y causante de grandes pérdidas económicas, aunque las infecciones agudas también constituyen una fuente importante de infección. A pesar de la importancia económica, sanitaria y epidemiológica de esta enfermedad, en Colombia son muy pocos los estudios publicados en este aspecto y no existe una clara evidencia de la prevalencia del VDVB a nivel regional. Objetivo. Detectar animales seropositivos y persistentemente infectados con el virus de diarrea viral bovina (VDVB) en bovinos de diferentes grupos etáreos del Piedemonte del Meta.

Materiales y métodos. Muestras de sangre fueron tomadas en cuatro fincas del Piedemonte del Meta (Cumaral, Villavicencio y Guamal) en diferentes grupos etáreos (vacas, novillas de vientre, terneros y toretes y toros) para un total de 124 animales. La sangre fue centrifugada y el suero obtenido fue usado para detectar los niveles de anticuerpos y antígenos a través de ELISA. Para evaluar los resultados de ELISA se realizó un análisis de chi cuadrado $\chi^{2}$ a través de tablas de contingencia. Resultados. Se encontraron diferencias significativas en los 
títulos de anticuerpos de las 4 fincas muestreadas $\left(p<0.001, \chi^{2}: 32.5\right.$, df: 6$)$. El $18.5 \%$ de los animales fueron seropositivos (23/124), 79.8\% seronegativos $(99 / 124)$ y $1.6 \%$ de animales sospechosos (2/124). Las vacas presentaron $12.1 \%$ de seropositividad (15/46), seguido por los terneros (5/46) y las novilla de vientre (3/19). Ninguno de los machos presentó niveles de anticuerpos detectables. Ninguna de las fincas reportó prácticas de vacunación contra el VDVB. Conclusiones. El presente estudio evidenció la presencia de animales seropositivos en 4 fincas lecheras y de doble propósito ubicadas en el Piedemonte del Meta; sin embargo, la presencia de anticuerpos no estuvo ligada a la presencia de animales persistentemente infectados. Se puede inferir que los bovinos seropositivos estuvieron eventualmente expuestos al virus lo cual favoreció la producción de anticuerpos. Basados en los resultados se puede sugerir que la posible fuente de infección puede estar relacionada con la introducción de animales nuevos a los hatos o el uso de semen congelado para los procesos de inseminación artificial. Apoyo financiero. Este proyecto fue financiado por la Dirección General de Investigaciones de la Universidad de los Llanos a través de la convocatoria pública de méritos para vinculación de profesores de planta No 001-P-2012.

Palabras clave: Diarrea viral, bovinos 


\title{
Atrial function in tachycardia-induced heart failure dogs
}

Vargas Pinto Pedro ${ }^{1}$ MV, MSc, Ph.D.' Pedraza Toscano Adriana ${ }^{2}$ MV, MSc, Ph.D. Fedorov Vadim ${ }^{3}$ Ph.D, Vecchiet Jonathan ${ }^{3}$ BSc., Hund Thomas ${ }^{4}$ Ph.D, Hamlin Robert $^{2}$ DVM, MSc, Ph.D, DACVIM, Carnes Carnes Pharm. D. ${ }^{3}$, Ph. D

${ }^{1}$ Facultad de Ciencias Agropecuarias. Universidad de la Salle. Bogotá, Colombia,

${ }^{2}$ The Ohio State University. College of Veterinary Medicine.

${ }^{3}$ The Ohio State University. College of Pharmacy.

${ }^{4}$ The Ohio State University. Dorothy Davis heart and Lung Institute. pavargas@unisalle.edu.co

\begin{abstract}
For years researchers have looked for the perfect model to study heart failure (HF), and thereby understand its mechanistic causes and consequences. Among those models, there is one, rapid pacing in dogs, that has been used for decades because it recreates the process in weeks to months, as happens in human beings. Rapid pacing has answered several questions on mechanisms of cardiac remodeling during heart failure and how the body responds to it in terms of changes in hormones and proinflammatory mediators. In this study we established in a non-invasive manner the effect of time-dependent effects of heart failure on atrial depolarization time and how this is associated with atrial size and function (structural remodeling) in mongrel dogs. At the in vitro level we examined the qualitative and quantitative effects of $\mathrm{HF}$ on atrial connexin 43. Atrial functional and structural remodeling during $\mathrm{HF}$, contributes to the generation and maintenance of the most common sustained arrhythmia found in human beings, atrial fibrillation. In this study, HF caused electrophysiological remodeling ( $P$ wave duration prolongation $p<0.05$ when baseline was compared to 2,3 and 4 months), structural remodeling (LA enlargement at the end of systole and diastole $p<0.05$ when baseline was compared to 2, 3 and 4 months), and dynamic functional remodeling such as tardy contraction of the caudal portion of the LA established by tissue Doppler interrogation ( $p<0.01$ when baseline was compared to 3 and 4 months). These findings closely mimic observations made in human and animal patients at risk for atrial fibrillation.
\end{abstract}

Key words: Tachycardia dogs. 


\title{
Valores de referencia de gases arteriales y electrolitos en caninos de la Sabana de Bogotá *
}

\author{
Trujillo Jurado C. A. ${ }^{1}$, Dalmau Barros E. A. ${ }^{2}$, Díaz Rojas C. A. ${ }^{3}$ y \\ Venegas Cortés C. A. ${ }^{4}$ \\ ${ }^{1}$ MV Universidad de La Salle, MSc., Docente de la Universidad de La Salle, \\ ${ }^{2}$ MV Universidad de La Salle, MSc., Docente de la Universidad de La Salle, \\ ${ }^{3} \mathrm{MV}$ Universidad de La Salle, Esp, MSc, PhD (c), Docente de la Universidad de La \\ Salle Esp, MSc (c), \\ ${ }^{4}$ MV Universidad de La Salle, MSc., Docente de la Universidad de La Salle \\ Docentes investigadores grupo de Medicina y Sanidad Animal, Programa de \\ Medicina Veterinaria, Facultad de Ciencias Agropecuarias, Universidad de La \\ Salle. \\ ceadiaz@unisalle.edu.co \\ * Son calculados obtenidos a partir de los valores medidos directamente.
}

\section{RESUMEN}

Introducción. La extrema sensibilidad de los gases y del pH a los diferentes cambios del organismo, el medio ambiente (altitud, presión atmosférica) y la ausencia de valores de referencia construidos en nuestro medio para nuestros pacientes, acarrea obligatoriamente la consulta de valores reportados en condiciones muy disímiles a las de nuestro medio, ocasionando posibles errores en la correlación clínica. Objetivo. Determinar valores de referencia de gases arteriales y electrolitos para caninos ubicados a la altura de la sabana de Bogotá, demostrando la variación que existe con la literatura reportada frecuentemente consultada. Metodología. El proyecto se realizó en el departamento de Cundinamarca, en la Sabana de Bogotá, en los municipios de Chía (2652 msnm), Cajicá (2558 msnm), Sopó (2650 msnm), La Calera (2718 msnm) y Bogotá (2630 msnm). Se utilizó una muestra arterial de 100 caninos registrados en la Asociación Club Canino Colombiano, de acuerdo a tallas definidas: A. 25 perros entre 1-10 kilogramos $(\mathrm{Kg})$; B. 25 perros entre 11-20 (Kg) ; C. 25 perros entre 21-30 (Kg); D. 25 perros superior a 31 kilogramos $(\mathrm{Kg})$; se utilizó el equipo de gases arterial I$\mathrm{STAT}^{\circledR}$ con cartucho $\mathrm{EG}^{+}$que arroja : $\mathrm{Na}+\mathrm{K}_{+}, \mathrm{TCO}^{*}$, iCa++, Hematocrito, Hemoglobina* ${ }^{*} \mathrm{pH}, \mathrm{PCO}_{2}, \mathrm{PO}_{2}, \mathrm{HCO}_{3}{ }^{*}, \mathrm{BEfect}^{*}, \mathrm{SO}_{2}{ }^{*}$. Se realizó estadística descriptiva para cada variable y obteniendo los límites de confianza para cada 
valor al $95 \%$ e intervalos con 1 y 2 desviaciones estándar. Entre los cuatro diferentes grupos por peso se realizó una comparación utilizando ANAVA así como prueba de Tukey en el programa Statistix 8.0. Resultados. Se obtuvieron diferencias estadísticamente significativas $(p<0,05)$, entre los grupos por peso, para los valores de $\mathrm{PO}_{2}$, al realizar la prueba de Tukey; se identificó que los grupos de $\mathrm{B}$ y $\mathrm{C}$ se comportaron igual; el grupo A se comportó diferente así como el grupo de $D$. De esta manera encontramos que la media para los grupos $B$ fue menor $y$ para el grupo $D$ fue mayor, a manera demostrativa y comparativa no probada estadísticamente, se evidenció diferencias importantes entre los valores de $\mathrm{pH}$, $\mathrm{PCO}_{2}, \mathrm{PO}_{2}, \mathrm{HCO}_{3-}, \mathrm{BEfect}, \mathrm{SO}_{2}$, con los valores reportados por la literatura. Conclusiones. A la altura de la Sabana de Bogotá, los caninos sanos presentaron diferencias en los valores de gases arteriales y balance ácido base, destacando disminuciones de la presión de los gases $\mathrm{CO}_{2}$ y $\mathrm{O}_{2}$, que influyeron de manera directa en las concentraciones del bicarbonato (más $\mathrm{PCO}_{2}$ ), ocasionando bajas debido a la compensación de tipo renal, enmascarando apariencia de imbalances, si no se correlacionan con la sintomatología clínica y el pH. Las diferencias entre grupos de peso no fueron frecuentes para los resultados de balance ácido base y electrolitos.

Palabras Clave: Gases arteriales, caninos, $\mathrm{PO}_{2}, \mathrm{PCO}_{2}, \mathrm{pH}$, Electrolitos, altura $2600 \mathrm{msnm}$. 


\title{
Seguimiento serológico de la Leptospirosis Bovina en fincas de la sabana de Bogotá
}

\author{
Díaz Rojas C. A. ${ }^{1}$, Dalmau Barros E. A. ${ }^{2}$, Venegas Cortés C. A. ${ }^{3}$ y \\ Trujillo Jurado C. A. ${ }^{4}$
}

${ }^{1} \mathrm{MV}$ Universidad de La Salle, Esp, MSc, PhD (c), Docente de la Universidad de La Salle, ${ }^{2}$ MV Universidad de La Salle, MSc., Docente de la Universidad de La Salle ${ }^{3}$ MV Universidad de La Salle, Esp, MSc (c), Docente de la Universidad de La Salle ${ }^{4}$ MV Universidad de La Salle, MSc., Docente de la Universidad de La Salle Grupo de Investigación en Medicina y Sanidad Animal, Facultad de Ciencias

Agropecuarias, Universidad de La Salle, Bogotá - Colombia ceadiaz@unisalle.edu.co

\section{RESUMEN}

Introducción. La leptospirosis es una enfermedad bacteriana zoonótica que ocurre en bovinos, su presentación se relaciona con factores predisponentes. Objetivo. Determinar la dinámica de la enfermedad y asociar los títulos a MAT con indicadores de estrés - cortisol y glicemia - y la asociación con la precipitación. Metodología. El trabajo se realizó en cuatro fincas lecheras de la sabana de Bogotá que llevan registros y con ciclo completo de producción, ubicadas en La Calera (finca 1), Sibaté (finca 2), Sopó (finca 3) y Tabio (finca 4). Se incluyeron fincas positivas a Leptospira. Un total de 78 animales fueron seleccionados y distribuidos en grupos etareos: vacas, novillas y terneras; el seguimiento serológico se llevó a cabo empleando la prueba estandarizada de microaglutinación (MAT), cada 45 días durante 12 meses con el fin de determinar la dinámica de la enfermedad y la relación de los títulos con indicadores de estrés y la variable precipitación pluviométrica. Animales con títulos mayores de 1:100 en

2 muestreos seguidos, se consideran positivos. Resultados. En general, los animales presentaron prevalencia mayor a L. Hardjo, seguida de L. Pomona y L. icterohaemorragiae, correspondientes al 12,8\%, 10,8\% y 7,3\%, respectivamente. La finca 4 tuvo una prevalencia del $34,12 \%$ a $L$. icterohaemorragiae, seguida por la finca 2 con 29,52\% a L. Hardjo y 27,7\% de seroprevalencia a L. Pomona, nuevamente en Tabio. La finca 2 tuvo las prevalencias más bajas a los serovares de Leptospira, ésta presenta las mejores condiciones sanitarias. La precipitación promedio fue mayor en la finca 4 , municipio Tabio $(4,8 \mathrm{~mm})$, seguida por la finca 3 
(con mayor drenaje), luego la finca 1 y por último la finca de Sibaté $(2,6 \mathrm{~mm})$, presentándose diferencias estadísticamente significativas entre ellas. En promedio los niveles de cortisol se relacionaron en forma directa con los niveles promedio de glicemia, esta tendencia se observó al principio y al final de los muestreos. Por fincas, el promedio de glicemia fue mayor en la finca 3, seguido por la 1 y 2 y más bajos en la finca 4 . Estos resultados de las fincas 3 y 1 presentan mayor desviación estándar, en la que pudo influir el mayor número de animales de diferente edad. Conclusiones. Se encontró prevalencia a Leptospira Hardjo, L. Pomona y $L$. icterohaemorragiae en bovinos de diferentes fincas de la sabana de Bogotá. La mayor precipitación pluviométrica puede relacionarse con mayor prevalencia a Leptospira spp. No hubo una tendencia clara entre los niveles de cortisol y glucosa en sangre como indicadores de estrés en los bovinos muestreados.

Palabras clave. Leptospirosis, MAT, bovinos, precipitación, cortisol 


\section{Respuesta serológica a herpesvirus bovino 1(BOHV-1) y herpesvirus bovino 5 (BOHV-5) en hatos del piedemonte llanero}

Vargas Diana S1 MV, MSc; Bohórquez Alejandro1; Góngora Agustín² MV, MSc, $\mathrm{PhD}$; Correa Jairo Jaime ${ }^{1} \mathrm{MV}, \mathrm{MSc}, \mathrm{PhD}$.

${ }^{1}$ Grupo de investigación en Microbiología y Epidemiología, Universidad Nacional de Colombia Sede Bogotá

${ }^{2}$ Grupo de investigación y genética animal (GIRGA) Universidad de los Llanos jiaimec@unal.edu.co dsvargasb@unal.edu.co

\section{RESUMEN}

Los herpesvirus bovinos (BoHV) están considerados entre los agentes infecciosos más importantes del ganado bovino. Particularmente, el herpesvirus bovino1 (BoHV-1) presenta una distribución mundial y es endémico en la mayoría de las poblaciones bovinas. En cuanto al Herpesvirus bovino 5 (BoHV-5), presenta una distribución geográfica limitada, se ha reportado principalmente en Sur América (Brasil y Argentina) y casos esporádicos en otros continentes. Estos dos virus pertenecen a la familia Herpesvirus, subfamilia Alfaherpesvirus genero Varicelovirus. El genoma de BoHV es un DNA de doble cadena de $137.821 \mathrm{pb}$ siendo el BoHV5 más largo. Los dos herpesvirus se relacionan antigénica y genéticamente, con una homología entre 70 a 87\%; sin embargo, los dos virus difieren en su capacidad neuroinvasiva y su neurovirulencia. El BoHV-1 se ha asociado con enfermedad respiratoria (rinotraqueitis bovina infecciosa-IBR), enfermedad genital (Vulvovaginitis y balonoprostitis) y abortos; a diferencia de BoHV-5 que se ha asociado principalmente con la presentación de meningoencefalitis. La determinación de la prevalencia de BoHV5 es laboriosa por métodos serológicos debido a que los dos herpesvirus son antigénicamente muy similares, y los dos virus comparten epítopes comunes, por lo tanto se ha observado reactividad cruzada en hatos vacunados o infectados conBoHV-1. Por lo anterior, se ha establecido que en regiones donde se lleva a cabo la vacunación rutinaria contra BoHV-1 el riesgo de presentación de BoHV-5 es menor. En Colombia, no hay reportes de enfermedad ocasionada por BoHV-5, aunque su presencia se sospecha ya que se ha encontrado en otros países del continente desde hace más de una década. Objetivo. El objetivo de este estudio fue 
determinar la presencia de anticuerpos para BoHV-1 y BoHV-5, así como también determinar la protección cruzada contra los dos herpesvirus en hatos del piedemonte llanero. Materiales y Métodos. Para este estudio, se analizaron 192 sueros provenientes de 10 fincas del municipio de Puerto López. Estos sueros se evaluaron mediante la técnica de seroneutralización viral para BoHV-1 y BoHV-5, (virus previamente titulados mediante la $T C I_{50}$ ) y empleando las línea celular MDBK. Resultados. En los sueros se evidenció la presencia de anticuerpos para BoHV en 158 (82.3 \%), de estos 156 (98.7\%) para BoHV-1 y 102 (64\%) para BoHV5. Así mismo, se evidenció que la mayoría de animales que tienen anticuerpos para BoHV1 tienen anticuerpos para BoHV5. Conclusiones. Los resultados confirman mayor prevalencia de BoHV-1 en la ganadería colombiana, sin embargo, animales con títulos altos para BoHV-1 muestran anticuerpos para BoHV-5, lo que confirma la reactividad cruzada entre los dos herpesvirus.

Palabras clave: herpesvirus bovino 1 y herpesvirus bovino 5, piedemonte llanero 


\section{Detección del virus de diarrea viral bovina en 4 regiones del país mediante la técnica molecular de RT-PCR.}

Villamil Reyes Viviana Vanadia', MV, MSc(c); Ramírez N Gloria ${ }^{1}, \mathrm{MV}, \mathrm{MSc}, \mathrm{PhD}$; Vera A Víctor. ${ }^{1}$, DMV, MSc, PhD; Correa Jairo Jaime ${ }^{1^{\star}}, \mathrm{MV}, \mathrm{MSc}$. PhD.

${ }^{1}$ Linea de Investigación en Microbiología y Epidemiología. Facultad de Medicina Veterinaria y de Zootecnia. Universidad Nacional de Colombia, Sede Bogotá.

jiaimec@unal.edu.co vvvillamilr@unal.edu.co

\section{RESUMEN}

El virus de la Diarrea Viral Bovina (VDVB) es un patógeno que afecta a los hatos bovinos, se caracteriza por generar diferentes presentaciones clínicas que pueden ir desde formas asintomáticas hasta la presentación de cuadros agudos de carácter entérico, reproductivo o respiratorio en los animales infectados. Está compuesto por un genoma ARN de cadena sencilla y polaridad positiva, el cual ha sido clasificado en 2 biotipos (citopático y no citopático) y en 2 genotipos (I y II) de acuerdo a su secuencia nucleotídica. Debido al alto impacto económico y sanitario de la entidad, se hace indispensable una rápida detección del VDVB en campo, brindando al productor herramientas diagnósticas altamente efectivas. Objetivo. Detectar el VDVB en bovinos pertenecientes a 4 regiones del país, a partir de la técnica molecular RT-PCR en muestras de campo y diagnosticar animales PI dentro de las explotaciones. Materiales y Métodos. En este estudio se emplearon 173 sueros de hembras bovinas, 19 sueros precalostrales y 20 muescas de oreja de los terneros recién nacidos, obtenidos durante los meses de Abril - Julio de 2013, provenientes de 4 explotaciones ganaderas ubicadas en los departamentos del Valle del Cauca, Santander, Cundinamarca y Antioquia. Para todos los sueros y muescas de oreja, se realizó extracción de RNA con el kit de extracción viral QIAamp Viral RNA (Qiagen®) y luego se realizó la síntesis de cDNA con el Kit Qiagen® OneStep RT-PCR. Se usó una pareja de primers que amplifican una región altamente conservada del genoma viral (5'UTR). Resultados. Se obtuvo un $\mathbf{7 , 6} \%$ de seropositividad en las hembras bovinas muestreadas y un $\mathbf{1 0 , 5 \%}$ de seropositividad en los terneros. Se evidenció un $\mathbf{5 \%}$ de positividad en las biopsias obtenidas a partir de cartílago de oreja de los terneros. La sensibilidad de la RT- 
PCR fue lograda por el empleo de RNA de la cepa de referencia NADL, la cual fue estandarizada previamente al procesamiento de las muestras, lo cual determinó la eficacia de la técnica molecular. La región de Santander mostró el mayor porcentaje de muestras positivas en hembras (4,1\%), seguido del Valle del Cauca $(2,92 \%)$ y finalmente, $0,58 \%$ en la región de Antioquia. En los terneros se evidenció una mayor tasa de seropositividad en la región de Santander $(10,5 \%)$, al igual que en la positividad de las muescas obtenidas de las orejas (5\%). Conclusiones. La RT-PCR desarrollada en este estudio permite la rápida, específica y sensible detección de VDVB en suero sanguíneo y biopsia de cartílago de oreja. A partir de esta técnica molecular se pueden detectar animales persistentemente infectados (PI) que se encuentren diseminando el virus en las explotaciones bovinas.

Palabras clave. Virus diarrea bovinos 


\section{Estandarización de una RT-PCR en tiempo real (QRT-PCR) para la detección del virus del sindrome reproductivo y respiratorio porcino (PRRSV) en Colombia}

Mancipe J Luisa Fernanda ${ }^{1 *}$, MV, MSc; Mendoza Eliana ${ }^{1}, \mathrm{Mv}, \mathrm{MSc}(\mathrm{C})$; Ramírez Gloria $^{1}, \mathrm{MV}, \mathrm{PhD}$; Vera Víctor Julio ${ }^{1}, \mathrm{MV}, \mathrm{PhD}$; Mogollón José Darío ${ }^{1}, \mathrm{MV}, \mathrm{PhD}$; Correa Jairo Jaime ${ }^{1^{*}}, \mathrm{MV}, \mathrm{PhD}$.

${ }^{1}$ Linea de Investigación en Microbiología y Epidemiología. Facultad de Medicina Veterinaria y de Zootecnia. Universidad Nacional de Colombia, Sede Bogotá. jiaimec@unal.edu.co Ifmancipej@unal.edu.co

\section{RESUMEN}

El síndrome reproductivo y respiratorio porcino (PRRS) es causado por un virus RNA de cadena sencilla y polaridad positiva, que pertenece a la familia Arteriviridae $y$ al género Arterivirus. Genera enfermedad respiratoria en cerdos jóvenes y considerables fallas reproductivas en cerdas incluyendo abortos, muerte fetal y lechones débiles. La rápida detección de PRRSV en muestras de campo es muy importante para lograr un control efectivo, reduciendo potencialmente serias pérdidas económicas generadas por brotes de la enfermedad. Objetivo. Estandarizar una QRT-PCR cuantitativa rápida y sensible para la detección de PRRSV a partir de diferentes muestras de campo. Materiales y Métodos. En este estudio se emplearon 372 sueros, 131 pulmones y ganglios linfáticos y 316 fluidos orales colectados entre 2012 y 2013, provenientes de 3 granjas ubicadas en el departamento Valle del Cauca. Para todos los sueros, pulmones, ganglios linfáticos y fluidos orales se realizó extracción de RNA con el kit de extracción viral QIAamp Viral RNA (Quiagen® cat No. 52906) y luego se llevó a cabo la síntesis de cDNA con High Capacity cDNA Reverse Transcription Kits (Applied Biosystems $\left.{ }^{\circledR}\right)$. Para la construcción de la curva estándar se empleó LightCycler 480 SYBR GREEN I Mastery una pareja de primers que amplifican una región altamente conservada (ORF7-ORF6). Resultados. La sensibilidad de la QRTPCR fue lograda por el empleo de RNA de la cepa de referencia VR2332, donde se logró obtener un rango de detección lineal de $9,52 \times 10^{5}$ hasta $9,52 \times 10^{10}$ número de copias por reacción, con una concentración que va desde $1,33 \times 10^{6}$ hasta $1,10 \times 10^{11}$, respectivamente, y con un coeficiente de correlación de 0.9949 . Para la 
reproducibilidad de la prueba se realizó RT-PCR convencional en paralelo con QRT-PCR. Se consideró que todas las muestras que se encuentren con un crossing point (CP) entre 15-32 son consideradas como positivas basado en la curva estándar construida. Al determinar porcentaje de positividad por muestras se estableció que para un total de 372 sueros analizados el $91 \%$ fueron negativos y el $9 \%$ fueron positivos, con cargas virales de 5.573 $\times 10^{7}$; para un total de 131 pulmones se encontró que el $92 \%$ fue negativo y el $8 \%$ positivo con cargas virales de $5.327 \times 10^{11}$; para los 131 ganglios linfáticos se observó que el $90 \%$ fueron negativos y el $10 \%$ positivos, con cargas virales de $4.662 \times 10^{6}$, mientras que para 308 muestras de fluidos orales se encontró que el $81 \%$ fueron negativas y el $19 \%$ fueron positivas, con cargas virales de $3.434 \times 10^{8}$. Conclusiones. La QRT-PCR desarrollada en este estudio permite la rápida, específica y sensible detección de PRRSV en las diferentes muestras de campo. Se pudo observar que la muestra donde se detectó mayor número de positivos fueron los fluidos orales, seguido de sueros, ganglios linfáticos y pulmones.

Palabras clave. Síndrome reproductivo y respiratorio, porcinos 


\section{Detección molecular de rotavirus equino en la sabana de Bogotá mediante la amplificación por PCR de la región VP7}

Herrera Heidy; Vargas Diana $S^{1^{*}}$ MV, MSc; Correa Jairo Jaime ${ }^{1} M V$, MSc, PhD. ${ }^{1}$ Grupo de investigación en Microbiología y Epidemiología, Universidad Nacional de Colombia Sede Bogotá

jiaimec@unal.edu.co

\section{RESUMEN}

El rotavirus es la principal causa de diarrea viral en una amplia variedad de animales domésticos e infantes; en potros, se reporta como una causa común de enteritis o diarrea. Este virus pertenece a la familia Reoviridae y se ha clasificado en 7 grupos (A-G). Las variaciones antigénicas y genéticas de sus proteínas externas VP6, VP7 y VP4, han permitido la clasificación del virus en grupo y tipos $G$ y $P$ respectivamente. El grupo $A$ de rotavirus es la causa más frecuente de diarrea en potros los cuales, son afectados dependiendo del estado inmunológico, carga viral y edad de cada individuo principalmente menores de 3 meses. El rotavirus equino (RVE) se reportó por primera vez en Inglaterra en 1975, desde entonces ha evidenciado alrededor del mundo. Objetivo. Detectar y aislar rotavirus de potros procedentes de la Sabana de Bogotá. Materiales y métodos. Se obtuvieron 12 muestras de materia fecal de potros con diarrea. Estas muestras se diluyeron en PBS, se sonicaron y centrifugaron para obtener el inoculo. El asilamiento viral se realizó en la línea celular MA-104, se espero a la formación de efecto citopático y posteriormente se realizó extracción de RNA viral con un kit comercial (QIAamp Viral RNA-Quiagen $\circledast$ ), y se hizo una RT-PCR empleando primers degenerados (Rota F2 deg y rota B3 deg) que amplifican un fragmento que codifica para la proteína VP7, sin diferenciar a tipo $G$ al que pertenecían. Resultados. El aislamiento viral se logró en 5/12 muestras empleadas; sin embargo, en todas las muestras fue necesario realizar pasajes ciegos para observar el efecto citopático característico (vacuolización, desprendimiento de la monocapa). En cuanto a la detección molecular, se logró la amplificación por PCR de la secuencia para VP7 en 7/12 muestras. Conclusiones. El estudio corresponde al primer trabajo que confirma la presencia del rotavirus equino 
empleando PCR en el país, a partir de estos resultados se espera obtener la caracterización molecular del virus, con el fin de determinar a qué tipo $G \circ P$ pertenecen, así como también determinar cuál es el tipo más prevalente en el país.

Palabras clave. Rotavirus sabana de Bogotá, equinos 


\title{
Efecto de la suplementación con silo de botón de oro (Tithonia diversifolia) en ovinos de ceba sometidos a pastoreo restringido con Brachiaria sp
}

\author{
Triana Meléndez Eduard Daniel ${ }^{1}$, Echeverría Infante Jhon Mateo ${ }^{1}$ y \\ Roa Vega María Ligia ${ }^{2}$ \\ ${ }^{1}$ Estudiantes de M.V.Z de la Universidad de los Llanos. \\ 2Z. Msc. Docente, Universidad de los Llanos; Escuela de Ciencias Animales \\ ligiaroa2607@gmail.com
}

\section{RESUMEN}

Introducción. El botón de oro (Tithonia diversifolia), es una planta forrajera adecuada para la alimentación de rumiantes (bovinos, cabras, ovejas y búfalos), con un alto nivel de proteína y degradabilidad en el rumen, bajo contenido de fibra y niveles aceptables de sustancias antinutricionales como fenoles y taninos. El follaje de botón de oro es rico en nitrógeno total, buena parte del cual está presente en aminoácidos y, en baja proporción, está ligado a la fibra dietética insoluble. Su concentración de proteína (de 18,9 a 28,8\%). Objetivo. Determinar si la suplementación con silo de botón de oro en la dieta para ovinos de ceba en pastoreo con Braquiaria sp y suplementados con $0.5 \%, 0.75 \%, 1 \%$ del peso vivo (PV) evaluando su efecto sobre la ganancia de peso, conversión alimenticia y consumo. Metodología. Fueron utilizados 12 ovinos (camuros) destetos con un promedio de peso de $12 \mathrm{~kg}$ distribuidos en un diseño completamente al azar cuatro grupos en corrales de dos metros $x$ dos metros y reposaban en cama profunda de viruta de madera para suministrar un ambiente confortable. Se organizaron los siguientes tratamientos T1: grupo control en pastoreo únicamente, T2, T3 y T4 animales en pastoreo suplementados con $0,5 \%, 0,75 \%$ y $1 \%$ del PV con ensilaje de botón de oro, respectivamente, además se les suministró agua y sal mineralizada a voluntad. Los animales, se adaptaron durante 10 días a las dietas para disminuir error experimental. El estudio se llevó a cabo en la Granja Barcelona en el Área Experimental de Ciencias Animales, perteneciente a la escuela de Ciencias Animales de la Universidad de los Llanos en el departamento del Meta. La toma de datos de campo se realizó en diarios de campos y pesando cada 10 días durante 70 días. Se ajustó el consumo del ensilaje de botón de oro 
cada 30 días ya que los animales aumentaran de peso y la cantidad suplemento se hizo con base al peso corporal. Resultados. El aumento de peso total fue menor $(P<0.05)$ para T1 $(19.68 \mathrm{~kg})$ en comparación con el T4 $(20.76)$, con lo otros tratamientos fueron similares. El aumento diario de peso fue mayor $(\mathrm{P}<0.05)$ para T4 (721.88 gr/día) en comparación con los demás tratamientos que se comportaron similar y no presentaron cambios. El consumo de materia seca (MS) día/gr fue mayor $(\mathrm{P}<0.05)$ para T4 $(1149,14)$ en comparación con T1 y T2 $(887,04$ y 998,70). Los cuatro tratamientos fueron similares para las variables conversión alimenticia, eficiencia alimenticia y coeficiente de eficiencia proteica. Conclusiones. El tratamiento que desarrollo mejores resultados fue T4, los ovinos fueron suplementados con el $1 \%$ de su PV con silo de botón de oro, obtuvo los mayores valores en : ganancia de peso con $24.02 \mathrm{~kg}$, consumo de forraje (pasto) en MS/día de $1080.96 \mathrm{gr}$, consumo de silo en MS/día de $240.21 \mathrm{gr}$, consumo de MS total con $1321.17 \mathrm{gr} /$ día y consumo de proteína total con 112.00, También presentó las mejores: conversión alimenticia (1:2.406), y eficiencia alimenticia con $61.20 \%$.

Palabras clave: forrajes arbustivos, silo, alimentación, rumiantes 


\title{
Aprovechamiento de Cratilya argentea y Saccharomyces cerevisiae en bovinos canulados
}

\author{
Roa Vega María Ligia ${ }^{1}$, Corredor Matus Ricardo ${ }^{1}$ y \\ Hernández Martínez María Cristina 2,
}

${ }^{1}$ Z Msc y M.V.Z Msc, Docentes de la Universidad de los Llanos, Escuela de Ciencias Animales.

2 M.V.Z. Esp. Profesional Planta de Lácteos Universidad de los Llanos ligiaroa2607@gmail.com

\section{RESUMEN}

Introducción. La calidad nutritiva de los forrajes se define por consumo voluntario, digestibilidad y eficiencia de nutrientes en el organismo. Las gramíneas en los Llanos Orientales, tienen poca disponibilidad de proteína, debido a la calidad de suelos que son de baja fertilidad y alta acidez, por lo tanto el ganado requiere suplementación. Objetivo. Evaluar el efecto de la suplementación con varios niveles de Cratylia argentea y Saccharomyces cerevisiae sobre la dinámica ruminal en bovinos fistulados, en pastoreo con Brachiaria decumbens. Metodología. Este experimento se realizó en la Universidad de los Llanos, Villavicencio (Meta). Se utilizaron ocho (8) bovinos machos fistulados en rumen (criollo $x$ cebú) con peso promedio de $350 \pm 20 \mathrm{Kg}$, distribuidos en doble cuadrado latino $(4 \times 4)$,sobrecambio simple, cuatro tratamientos con probiótico y cuatro sin probiótico. Los animales estuvieron en pastoreo continuo con Brachiaria decumbens, sal mineralizada y agua a voluntad. Los tratamientos fueron: T0: pastoreo; T1, T2 y T3: pastoreo y suplementados con $0.1 \%, 0.15 \%$ y $0.2 \%$ de materia seca (MS) de Cratylia argentea, de peso vivo, con y sin probiótico: Saccharomyces cerevisiae, a razón de $10 \mathrm{ml} /$ animal/día administrada vía oral (dosis $2.0 \times 10^{4} \mathrm{UFC} / \mathrm{ml}$ por cada 35 kilogramos). Se realizaron curvas de degradación a las $0,6,12,24,48$ y 72 horas de la MS (DMS), nitrógeno total (DNT), Fibra detergente neutro (DFDN) y fibra detergente ácido (DFDA), utilizando el método in situ con bolsas de nylon. También se evaluó en líquido ruminal: $\mathrm{pH}$, nitrógeno amoniacal (N-NH3) y ácidos grasos volátiles (AGV), a las 0, 4, 9 y 12 horas. La Cratylia argentea necesaria para este experimento estaba establecida en las unidades forrajeras en bancos de proteína, se realizaron podas cada dos 
meses, deshidratando las hojas en secadores al medio ambiente. Resultados. La adición de probiótico y de cratilia incrementaron $(P<0,05)$ : DMS, DFDN, DFDA y DNT del braquiaria y cratilia. Se observó que la composición de los forrajes también influyó en el uso del probiótico puesto que en caso del pasto braquiaria, la DMS, DFDN, DFDA y DNT a las 72 horas fueron superiores $(P<0,05)$ con T3, lo mismo sucedió con la pared celular de cratilia que se degrado en mayor proporción con T3, comparado con los demás tratamientos. Antes de que los nutrientes inicien su fermentación existe una fase de latencia o colonización del forraje llamada fase lag, la cual fue menor $(\mathrm{P}<0.05)$ con la adición de probiótico. Los AGV, el T3 y con probiótico fue mayor la cantidad $(P<0.05)$ de ácidos acético y propiónico, aunque el promedio la segregación de acético y butírico fueron similares, mientras que con propiónico en el nivel de cero \% de cratilia presentó el mayor valor $0,571 \mathrm{gr} / \mathrm{litro}$ de liquido ruminal. Conclusiones. La adición de probiótico favorece en mayor grado la degradación de de cratilia y braquiaria en comparación con el nivel cratilia, aunque se observa un efecto aditivo en T3. En forrajes con mayor contenido de fibra como braquiaria la acción del probiótico es mayor que en la leguminosa (cratilia).

Palabras clave: Probiótico, leguminosas forrajeras, degradabilidad. 


\title{
Cinética de la degradación ruminal in situ e in vitro estimada en diez forrajes
}

\section{Kinetics of ruminal degradation in situ and in vitro estimated in ten fodders}

\author{
Navarro Ortiz Cesar A. ${ }^{1}$, M.V.Z., Roa Vega María L. ${ }^{1}$, Zoot, Esp, MSc \\ "Comparación de la técnica de digestibilidad in vitro con la in situ de diez forrajes \\ en bovinos rumino-fistulados en el piedemonte llanero del Meta" \\ ${ }^{1}$ Grupo de Agroforesteria, Facultad de Ciencias Agropecuarias y Recursos \\ Naturales, Dirección General de Investigaciones, Universidad de los Llanos, \\ Villavicencio, Colombia. \\ ligiaroa2607@gmail.com
}

\section{RESUMEN}

Antecedentes. El consumo y la digestibilidad, son temas de gran interés para los nutricionistas, puesto que en la producción animal se requiere de alimentos con alta aceptación y excelente aprovechamiento, con bajas pérdidas de nutriente por excretas. Objetivo. Evaluar la cinética de degradación ruminal estimadas mediante las técnicas de digestibilidad in situ e in vitro de diez forrajes. Métodos. Se escogieron las leguminosas Bauhinia variegata, Anadenanthera (Piptadenia) peregrina, Cratylia argentea, Brownea ariza, Gliricidia sepium y Delonix regia; las gramíneas Brachiaria decumbens y Pennisetum purpureum; y las arbustivas no leguminosas Tithonia diversifolia e Hibiscus rosa-sinensis. Los forrajes fueron recolectados a una edad de rebrote de 60 días, y se realizó un análisis nutricional preliminar, en el cual se determinó MS, NT y FDN. Con la información obtenida se estableció la curva y tasa de degradación de MS, FDN y NT a las 6, 12, 24, 48 y 72 horas. El diseño estadístico fue un análisis de varianza para determinar los rangos de desviación entre las dos técnicas. Las variables evaluadas fueron los promedios in situ e in vitro de la degradación ruminal $(6,12,24,48$ y 72 horas) de la MS, FDN y NT de los 10 forrajes. Los datos se analizaron aplicando la prueba T-Student para comparación entre medias. Resultados. La diferencia estadística $(p<0,05)$ de los promedios in situ e in vitro de digestibilidad de la MS, fue del $100 \%$ en cinco forrajes; $60 \%$ en cuatro forrajes; y en un forraje fue del $80 \%$. En la FDN fue del $100 \%$ en siete forrajes; $80 \%$ en dos forrajes; y en un forraje fue del $60 \%$. En el NT fue del $100 \%$ en tres forrajes; $80 \%$ en cinco forrajes; $y$ en dos forrajes fue 
del $60 \%$. Conclusiones. Existen diferencias entre la cinética de degradación ruminal estimadas mediante las técnicas in situ e in vitro para la MS, FDN y NT en los forrajes estudiados. Además se encontró en el $63,333 \%$ de los casos una mejor tasa y cinética de degradación mediante la técnica de digestibilidad in situ.

Palabras Clave: Digestión, degradación, rumen, gramíneas, leguminosas y no leguminosas. 


\section{Ensilajes con forrajes arbóreos}

Roa Vega María Ligia ${ }^{1}$, Plazas Borrero Camilo Hernando ${ }^{2}$ y Cuellar Leuro Enid ${ }^{3}$

'Zootecnista, Esp. Msc. Docente de la Universidad de los llanos, Villavicencio, Meta, Colombia; ${ }^{2}$ Médico Veterinario Zootecnista, Esp., Docente de la universidad de los Ilanos; ${ }^{3}$ Médica Veterinaria Zootecnista, Profesional de Apoyo, Laboratorio de Nutrición Animal, Universidad de los llanos

\section{ligiaroa2607@gmail.com}

\section{RESUMEN}

Introducción. Las especies arbóreas y arbustivas se vienen utilizando con buenos resultados en la alimentación de rumiantes. La zona del pie de monte llanero en Colombia tiene épocas críticas de verano, para lo cual es necesario proponer alternativas de alimentación. Es por esta razón que la presente investigación se encaminó a evaluar la calidad nutricional de ensilajes de cuatro especies forrajeras que se han establecido en la zona: veranera (Cratylia argentea), Cayeno (Hibiscus rosa-sinensis) cajeto o nacedero (Trychanthera gigantea) y Botón de oro (Titonia diversifolia). Materiales y Métodos. La investigación se realizó en la Universidad de los Llanos, Meta, Colombia. Estas cuatro especies se establecieron en parcelas, se podaron a los 60,90 y 120 días, cosechando sus hojas, las cuales fueron conservadas en microsilos de 5 kilogramos, dejando cuatro periodos de maduración (0,30,60, 90 días). El diseño experimental fue completamente a la azar con arreglo factorial: $4 \times 3 \times 4 \times 3$. (4 especies, 3 tiempos de corte, 4 de conservación del forraje por tres replicaciones). A los ensilajes se les realizó análisis bromatológico: Materia seca (MS), cenizas, grasa, proteína, fibra cruda (FC), fibra detergente neutro (FDN), fibra detergente ácido (FDA). Para la evaluación de la degradabilidad de la materia seca (DMS), se utilizaron 4 bovinos fistulados distribuidos en un cuadrado latino (4x4) con las 4 especies, con una duración de 10 días de adaptación y 4 de toma de datos. Se determinó la curva de degradabilidad de la MS (6, 12, 24, 48 Y 72 horas) y se midió el nitrógeno amoniacal (N-NH3) en el líquido ruminal. Resultados. La veranera mostró la mayor MS: $(P<0.05)$ en comparación con las otras especies. Se observó un aumento de la MS, FDN, FDA y lignina $(P<0.05)$ a medida que aumentaba el 
tiempo de maduración del ensilaje. En las cuatro especies La proteína decreció $(\mathrm{P}<0.05)$ con mayor tiempo de maduración del ensilaje. La DMS del cayeno presentó un mayor porcentaje $(\mathrm{P}<0.05)$ en los diferentes tiempos de corte y días de maduración observando que se encuentra en un rango entre $65 \%-90 \%$. El Botón de oro mostró la menor DMS $(\mathrm{P}<0.05)$ con un rango entre $50 \%-60 \%$. Las mayores concentraciones de $\mathrm{N}-\mathrm{NH} 3$, se observaron en cajeto y cayeno, debido a la alta degradabilidad de la MS. Conclusiones. Estas especies, pueden ser una alternativa de suplementación para las épocas críticas del Piedemonte llanero de Colombia para mantener el equilibrio en la producción animal.

Palabras clave: arbustivas, conservación, ensilajes 


\title{
Recuperación de suelos degradados por compactación estableciendo un sistema silvopastoril, para ganadería doble propósito, Piedemonte Llanero Colombiano
}

\author{
Plazas B. Camilo H. ${ }^{1}$ MVZ, Esp, M.Sc y \\ Sánchez M. Hugo Vladimir ${ }^{2}$ MVZ, Esp, M.Sc. \\ 1-2Docentes Universidad de los Llanos. Facultad de Ciencias Agropecuarias y \\ Recursos Naturales. Escuela de Ciencias animales. Programa de Medicina \\ Veterinaria y Zootecnia. \\ cplazasb@unillanos.edu.co
}

\section{RESUMEN}

Introducción. La ganadería es la principal actividad económica del Piedemonte Llanero, siendo la fuente alimenticia los forrajes de pastoreo (Brachiaria). Inicialmente muestran una productividad alta, después de varios años se empiezan a degradar por pastoreo excesivo (Compactación). Objetivos. Generar alternativas que disminuyan en corto tiempo el efecto de la compactación de los suelos en los sistemas de producción agropecuarios. Metodología. Se estableció como cobertura y abono verde la leguminosa Mucuna pruriens durante nueve meses, posteriormente se sembró Tithonia diversifolia y Cratylia argéntea para consumo y Gliricidia sepium, Swinglia sp, y Eritryna glauca para la formación de cercas vivas. Se realizó pastoreos con periodos de ocupación de un día con cinco animales por hectárea. Para el análisis estadístico se utilizo el programa SPSS, prueba T con comparación de medias Duncan. Resultados. Se presentó aumento con P>0.05 en: Materia Orgánica (\%) de 7.6 en suelo degradado (SD) a 17 en el suelo recuperado (SR), Ca (meq/100g de suelo) de 0,40 (SD) a 1 (SR), saturación de bases (\%) 15,4 (SD) a 38,08 (SR), actinomicetos (U.F.C.) de 8.000 (SD) a 40.000 (SR), bacterias (U.F.C.) de 100.000 (SD) a 200.000 (SR), hongos (U.F.C.) de 4 millones (SD) a 5 millones (SR), necromasa (Ton/ha) de 1.9 (SD) a 5.8 (SR), raíces (Ton/ha) de 3.4 (SD) a 7.1 (SR). Se presentó disminución con $\mathrm{P}>0.05$ en Al (meq/100 g de suelo) de 3,45 (SD) a 2 (SR), saturación de Al (\%), de 84,5 \% a $61,9 \%$ y en la temperatura a través del suelo en $1^{\circ} \mathrm{C}$. respectivamente. En el (SD), a la profundidad de $0 \mathrm{~cm}$ se debe aplicar una fuerza $\left(\mathrm{kg} / \mathrm{f} / \mathrm{cm}^{2}\right)$ de 13 ; a 10 $\mathrm{cm}$, de 19,5; a $20 \mathrm{~cm}$ de 21 , terminando a los $50 \mathrm{~cm}$ con 19,6, lo que indica que 
este suelo presenta síntomas de gran compactación. En el (SR), a $0 \mathrm{~cm}$ solamente se debe aplicar una fuerza $\left(\mathrm{kg} / \mathrm{f} / \mathrm{cm}^{2}\right)$ de 0,75 ; a $10 \mathrm{~cm}$ de 9,5; a $20 \mathrm{~cm}$ de 13.5 , terminando a los $50 \mathrm{~cm}$ con 17,6. Conclusiones: Con la metodología planteada indica que este suelo recuperó su estructura, disminuyendo notoriamente los síntomas de compactación.

Palabras clave: Abonos verdes, Recuperación suelos, Compactación, arboles 


\title{
Caracterización productiva, nutricional y económica de los productos de la
} Caña de Azúcar (Saccharum officinarum), en la subregión del piedemonte Ilanero en el Departamento del Meta, para la fabricación de concentrados y/o suplementos para animales

\author{
Monroy Ochoa Néstor ${ }^{1}$, Cárdenas García Darío ${ }^{2}$, Pacheco Camilo Ernesto ${ }^{3}$ y \\ Barajas Pardo Diana Patricia ${ }^{4}$ \\ 'Z. Esp, MSc (C). ${ }^{2}$ M.V.Z. MSc. PhD. ${ }^{3}$ M.V.Z. Esp. ${ }^{4}$ M.V. PhD. (C). \\ nestor.monroy@campusucc.edu.co
}

\section{RESUMEN}

Introducción. El aumento en el precio de la melaza de caña ha generado un incremento en los costos de producción del sector pecuario, gracias a que esta materia prima es utilizada directamente en la alimentación animal o como suplemento nutricional, en forma de concentrados o bloques nutricionales comerciales. Por lo anterior, es importante plantear posibles soluciones a la sustitución de la actual demanda de melaza. En la subregión del piedemonte Llanero, en el departamento del Meta, existe una alto nivel de producción del melado de caña por parte de los pequeños y medianos productores de la región. De esta forma se busca incrementar la productividad, la rentabilidad y la competitividad de estos productores y de los ganaderos, gracias a que en la región tienen asiento sistemas de producción en ganadería equina y bovina como el doble propósito, leche, carne y ganadería de reproducción. Objetivos. Este proyecto tiene como objetivo principal identificar la actividad productiva, nutricional y económica de los productos de la caña de azúcar (Saccharum officinarum), en el departamento del Meta, mediante el estudio de sustitución de la melaza por el melado de caña en la generación de suplementos proteico energéticos. De igual manera se pretende diagnosticar las áreas de cultivo de producción de caña y los ingresos percibidos por las ventas, se caracterizaran nutricionalmente (Energía, Proteína, Energía y Minerales) el melado de caña de azúcar producido en el departamento del Meta y se identificaran las alternativas de impacto en la diversificación o sustitución de la melaza por el melado de caña en los pequeños y 
medianos productores de caña. Metodología. La presente investigación es de tipo descriptivo. En una primera fase, se identificará y recolectará información de pequeños y medianos productores (donde se indagaran aspectos productivos, económicos, sociales y ambientales) de caña. Se medirá de manera independiente las variables: producción, consumo e ingreso. Para el análisis estadístico se utilizara un muestreo por conglomerados. Se recolectaran muestras de productos de caña (Melado y Panela) y se realizará el análisis bromatológico (Calidad nutricional) (AOAC, 1982), el valor energético (Calorías) y la cantidad de sacarosa que presentan estos compuestos representados en (Grados Brix). Finalmente, para el desarrollo de este proyecto se censara la producción regional de melado de caña, caracterizando en el número y ubicación de las unidades productivas, extensión de cultivo y cantidades de producto producido. La información cualitativa y cuantitativa resultante del muestreo del proyecto se analizará en el programa estadístico SPSS.

Palabras clave: melaza, melado de caña, conglomerado 


\title{
Efecto de la suplementación de diferentes niveles de glicerol en vacas holstein en postparto bajo condiciones de pastoreo.
}

\author{
Cardozo Jesús Alberto ${ }^{1}$, Cucunubo Luis Gabriel${ }^{2}$ y Sánchez José Luis ${ }^{3}$ \\ ${ }^{1}$ Est FMVZ Fundación Universitaria San Martin, Bogotá, Colombia, \\ ${ }^{2}$ MV, MSc Departamento de Salud Animal, FMVZ, Universidad de Tolima, Ibagué, \\ Colombia, FMVZ, ${ }^{3} \mathrm{MV}$, MSc Fundación Universitaria San Martin, Bogotá, \\ Colombia.

\section{jesus.cardozo.o@est.sanmartin.edu.co}

\section{RESUMEN}

El impacto económico de las enfermedades metabólicas en la producción láctea, nos lleva a la búsqueda de materias primas de subproductos agroindustriales que sean viables económicamente para la prevención de estas, como es el glicerol, subproducto del proceso de biodiesel. El objetivo de este estudio fue determinar el efecto de dos niveles de inclusión de suplementación de glicerol en la producción láctea, condición corporal, determinación de cuerpos cetónicos y actividad ovárica en bovinos de raza Holstein en condiciones de pastoreo. Se utilizaron 20 vacas asignadas aleatoriamente a los siguientes tratamientos: $\mathrm{T} 0=\sin$ glicerol, $\mathrm{T} 1=500$ $\mathrm{mL}$ de glicerol y T $2=1000 \mathrm{~mL}$ de glicerol; con un período de adaptación de 7 días y 42 días experimentales. Se evaluaron semanalmente las variables de producción láctea, condición corporal (según Ferguson, 1995), cuerpos cetónicos en orina (Test Rothera) y actividad ovárica cada 14 días por palpación rectal. Los datos de producción láctea fueron analizadas como medidas repetidas en el tiempo a través del procedimiento Proc Mixed (SAS 9.0), utilizando al animal (tratamiento) como sujeto y las medias de la semana 0 se utilizaron como una covariable en el modelo y ajustadas por el LSMEANS de PROC MIXED. Los modelos fueron probados para la función lineal y cuadrática más adecuada obtenidas mediante PROC GLM (SAS 9.0). Los datos de condición corporal se analizaron por el test no paramétrico de Wilcoxon (SAS 9.0) y se graficaron usando el software gráfico GraphPad Prism 5. La determinación de cuerpos cetónicos en orina y actividad ovárica se analizaron por el Test de $x^{2}$ de PROC FREQ (SAS 9.0.). La producción láctea presento una diferencia significativa entre tratamientos $(P<0,05)(T$ 0: 23,96, 
T 1: 25.46, T 3; 25,88), presentando una respuesta creciente para la inclusión de glicerol ( $\mathrm{T} 1=1,48 \mathrm{Lts} /$ día; $\mathrm{T} 2=1,9 \mathrm{Lts} /$ día) con respecto al tratamiento control, no presento diferencias significativas, en la determinación cuerpos cetonicos, condición corporal y actividad ovárica entre tratamientos, pero se presentó efecto significativo para actividad ovárica de semana $(P=0.018)$. Se concluye de acuerdo al grado inclusión de glicerol en bovinos de leche aumenta la producción láctea en una respuesta creciente.

Palabras Claves: glicerol, producción láctea, cuerpos cetonicos, actividad ovárica 


\title{
Determinación de los niveles de proteína bruta y de energía metabolizable óptimos para codornices en fase de postura
}

\author{
Hurtado Nery Víctor Libardo ${ }^{1}$, Torres Novoa Diana Milena² y \\ Ocampo Duran Alvaro ${ }^{1}$
}

'Z M.V.Z PhD, Profesores, Universidad de los Llanos.

${ }^{2}$ M.V.Z. MSc. Profesional Maestria SSSPAT Universidad de los Llanos

\section{vhurtado@unillanos.edu.co}

\section{RESUMEN}

Introducción. En la formulación de raciones para codornices, son utilizados requerimientos nutricionales establecidos en otros países, datos que resultan contrastantes, considerando que el mejoramiento genético de las aves ha sido continuo, llevando a incrementos apreciables en precocidad, conversión alimenticia y postura, lo cual indica que las exigencias de proteína, energía, aminoácidos y minerales, se deben revisar y actualizar frecuentemente. Objetivo. Estimar los niveles de proteína bruta y energía metabolizable óptimos para codornices japonesas en fase de postura en condiciones tropicales. Metodología. Este experimento se realizó en Unidad de especies menores de la Universidad de los Llanos, Villavicencio, Colombia. Fueron utilizadas 480 codornices de 34 días de edad, distribuidas en un diseño experimental completamente al azar, en un arreglo factorial de $4 \times 4$, cuatro niveles de proteína $(17.5,19.0,20.5$ y $22.0 \%$ ) y cuatro niveles de energía metabolizable (2750, 2850, 2950 y $3050 \mathrm{kcalEM} / \mathrm{kg})$, con tres repeticiones y 10 aves por repetición, para un total de 48 unidades experimentales. Las raciones experimentales, fueron elaboradas con maíz, torta de soya, mogolla de trigo, fosfato bicálcico, carbonato de calcio, aceite vegetal, premezcla vitamínico-mineral, sal, L-lisina, DL-metionina y material inerte. La composición nutricional de los ingredientes utilizados en la ración fue determinada en el Laboratorio de Nutrición Animal de Unillanos. Las aves fueron alojadas durante 26 semanas en jaulas de alambre, en módulos de cinco pisos y tres divisiones por piso de $40 \times 40 \mathrm{~cm}$, dotadas de comederos y bebederos automáticos tipo copa, el suministro de alimento y agua fue a voluntad. Las variables estudiadas fueron producción de huevos, peso del huevo, consumo 
diario de ración, conversión alimenticia y las características de calidad interna del huevo. Los resultados fueron procesados en el programa SAEG, sometidos a análisis de variancia y de regresión polinomial al 5\% de probabilidad. Resultados. No hubo interacción significativa $(P>0,05)$ entre los niveles de PB y EM para las variables en estudio. Al análisis de regresión, los niveles de proteína influenciaron de forma linear el peso del huevo y de forma cuadrática $\left(y=-0.0038 x^{2}+0.1456 x-\right.$ $0.5771, R^{2}=75.7$ ) la producción de huevos, la conversión alimenticia relacionada con $\mathrm{kg}$ de ración/docena de huevos y $\mathrm{kg}$ de ración $/ \mathrm{kg}$ de huevo. Los niveles de proteína y de energía no influyeron en el consumo diario de ración $(p>0,05)$, ni sobre las características de calidad interna (peso de la yema, peso y altura del albumen y unidades Haug) del huevo, sugiriendo que los nutrientes contenidos en las raciones son suficientes para atender las funciones de producción y mantenimiento de las aves. Conclusiones. Las exigencias de proteína bruta y de energía metabolizable para codornices japonesas en fase de postura y en condiciones de clima cálido, se estiman en $19,16 \%$ y $2791 \mathrm{kcal} / \mathrm{kg}$ de energía metabolizabe respectivamente. Los niveles de proteína bruta y de energía metabolizable no afectaron la calidad interna del huevo.

Palabras clave: Coturnix japónica, exigencias nutricionales, producción de huevos, unidades Haug. 


\title{
Digestibilidad y desempeño de codornices japonesas en fase de postura utilizando algunos alimentos energéticos
}

\author{
Hurtado Nery Víctor Libardo ${ }^{1}$ y Torres Novoa Diana Milena ${ }^{2}$, \\ ${ }^{1}$ M.V.Z PhD, Profesor, Universidad de los Llanos. \\ ${ }^{2}$ M.V.Z. MSc. Profesional Maestría SSSPAT Universidad de los Llanos \\ vhurtado@unillanos.edu.co
}

\section{RESUMEN}

Introducción. La alimentación de codornices depende de la industria de concentrados, dichos balanceados en general, son elaborados principalmente con maíz como fuente energética. En la búsqueda de ingredientes alternativos con el propósito de disminuir los costos de producción, es necesario conocer y la composición química y digestibilidad de esos alimentos, para ser incorporados con eficiencia en las dietas para codornices japonesas en fase de postura. Objetivo. Determinar la digestibilidad de proteína bruta (EB) y de energía bruta (EB) y evaluar el desempeño de codornices japonesas alimentadas con raciones conteniendo ingredientes energéticos alternativos en sustitución al maíz.

Metodología. Los experimentos fueron realizados en la unidad de codornices de la Universidad de los Llanos. Para determinar el coeficiente de digestibilidad aparente, CDA, se utilizó una ración referencia y cuatro dietas experimentales (sustitución de $30 \%$ de la dieta referencia por el alimento evaluado) en un diseño experimental completamente al azar con 5 tratamientos, tres repeticiones y 10 aves por repetición, la duración fue de 12 días, siete de adaptación a las jaulas y a las raciones y cinco días para la recolección de muestras, aplicando la técnica de coleta total de heces, los análisis de composición química de alimentos y dietas experimentales fue realizado en el Laboratorio de Nutrición Animal de Unillanos. Para establecer los parámetros de producción las aves fueron distribuidas en un diseño experimental completamente al azar con cinco tratamientos, cinco repeticiones y 10 aves por repetición, durante 24 semanas, alojadas en jaulas de alambre y dotadas de comederos lineales y bebederos automáticos tipo chupeta. Los datos fueron procesados y sometidos a análisis de varianza y comparación de 
medias para el experimento de desempeño zootécnico en el programa SAEG. Resultados. Los CDA de EB no presentaron diferencias $(p<0,05)$ entre los alimentos evaluados. Los CDA de proteína bruta y de energía fueron de 76.8, $71.6,57.9$ y $70.4 \%$ y $90.0,89.7,90.5$ y $89.9 \%$ para granza de arroz, harina de arroz, harina de yuca y harina de plátano respectivamente. La inclusión de granza de arroz, mejoró la producción de huevos $(p<0,05)$, que fue de $87.4 \%$ y la cantidad de ración por docena de huevos $(0.359 \mathrm{~kg})$. No hubo influencia $(p>0,05)$ de la inclusión de los ingredientes alternativos en sustitución parcial del maíz sobre el peso del huevo, los $\mathrm{kg}$ de ración/kg de masa de huevo, el consumo diario de ración ni las características de calidad del huevo. Conclusiones. Los alimentos alternativos presentan valores relativos altos de CDA de PB y EM, no afectan las características de calidad del huevo, lo que los constituyen en una alternativa para la sustitución del maíz como fuente energética en la alimentación de codornices. La granza de arroz puede sustituir hasta en $50 \%$ al maíz, como fuente energética en la dieta.

Palabras clave: Coeficiente de digestibilidad, calidad del huevo, conversión alimenticia, Coturnix japónica. 
Tiempo de maduración del ensilaje de botón de oro (Tithonia diversifolia) determinando la influencia en su digestibilidad in vitro.

${ }^{1}$ Alarcón Hernández Dairo Julián, ${ }^{1}$ Ríos Velandia Andrea Patricia, ${ }^{2}$ Céspedes Sanabria Daniel Alexander, ${ }^{3}$ Roa Vega María Ligia

${ }^{1} \mathrm{MVZ}$, UNILLANOS; ${ }^{2} \mathrm{cMSc}$, Docente UNILLANOS, ${ }^{3} \mathrm{MSc}$, Docente UNILLANOS dances71@hotmail.com

\section{RESUMEN}

Introducción. En la zona de los Llanos Orientales existen dos períodos climáticos, el seco y el de lluvias. En el primero los animales se ven sin pastos y forrajes, afectando su capacidad productiva, por lo tanto se requiere de alimento para superar la crisis en estos períodos, siendo una alternativa los ensilajes de arbustivas como lo es el Botón de oro (Tithonia diversifolia). Objetivo. Evaluar la calidad nutricional del ensilaje de Botón de oro sometido a diferentes tiempos de maduración y su efecto en la digestibilidad in vitro. Metodología. En el experimento se realizaron ensilajes que comprenden diferentes días de maduración, entre los cuales están 1, 3, 7,15, 28, 42, 63, 91 y 119, de fermentación anaeróbica, con el fin de realizar comparaciones de su calidad nutricional y el efecto del tiempo sobre ella, la etapa de corte de la planta para la realización de todos los ensilajes fue en prefloración. Para el procedimiento de evaluación de calidad nutricional los ensilajes se procesaron extrayendo tres muestras de tres silo-bolsa de cada uno de los tiempos referidos, para conformar una muestra integrada que se proceso en el laboratorio de Nutrición Animal. Las variables nutricionales a evaluar fueron: materia seca (MS), nitrógeno total (NT) y fibra detergente neutra FDN. Para el desarrollo del procedimiento de digestibilidad in vitro se realizó con la técnica desarrollada por, Van Soest et al., 1991. Resultados. Se modificaron algunos pasos del procedimiento, que consistieron en una incubación de la muestra del alimento con líquido ruminal a $39^{\circ} \mathrm{C}$, junto con un sustrato denominado saliva de Mc Dougall. Inicialmente se extrajo la parte semilíquida de la ingesta situada en el rumen, luego se filtró en un vaso estéril de $250 \mathrm{ml}$, el líquido extraído se mezcló con la solución de Mc Dougall previo al inicio de la incubación, esta mezcla se adicionó a las muestras a procesar (Tithonia 
diversifolia) en tubos de ensayo. El tubo con inoculo se mantuvo a una temperatura de $39^{\circ} \mathrm{C}$, en un baño de maría, con un tapón y lleno a capacidad evitando la oxigenación del material. Luego el material fue extraído diferentes horas de digestibilidad que comprenden $6,12,24,48$ y 72 , posterior a esto el material fue filtrado para estimar la digestibilidad de los nutrientes previamente determinados (MS, NT, FDN). Conclusión. Con estas modificaciones determinó el mejor tiempo de maduración del ensilaje, el cual conservo las características nutricionales óptimas para ser ofrecido como suplemento alimenticio a rumiantes.

Palabra clave. Botón de oro digestibilidad in vitro 